\title{
Optimal Unemployment Benefits in the Presence of Informal Labor Markets
}

\author{
Martin Gonzalez-Rozada \\ UTDT
}

\author{
Hernán Ruffo* \\ UTDT
}

\begin{abstract}
May 30, 2016
Abstract

We assess optimal unemployment benefit level and duration in a labor market with many informal jobs. Using administrative data from Argentina, a country with high informality, we exploit discontinuities in duration, and a reform that increases benefits. We find that increasing benefits hardly extends unemployment spells but raises re-employment wages. In contrast, extending unemployment benefits prolongs unemployment spells with no effect on re-employment wages. In a search model, we derive sufficient statistics to analyze the welfare effects of a reform that increases benefits by shortening duration. Calibrating our formula using our empirical results, we find that welfare would increase with higher benefits and shorter duration.
\end{abstract}

Keywords: Unemployment Insurance, Severance Payments, Regression discontinuity.

JEL classification: C41, I38, J64, J65.

\footnotetext{
${ }^{*}$ We would like to thank Robert Lalonde, Carmen Pages, Verónica Alaimo, Manuel Arellano, Claudio Michelacci, Stéphane Bonhomme, Enrique Kawamura and other seminar participants at IADB, SOLE/EALE, LACEA, CEMFI, UTDT and at UDESA as well as two anonymous referees for their helpful comments. We also thank Lucas Ronconi who helped us with the description of unemployment insurance and severance pay in Argentina for an earlier paper. We thank the "Dirección Nacional de Estudios y Estadísticas Laborales" from the Ministry of Labor, Employment and Social Security of Argentina for granting us access to the data and processing our codes, making this work possible. We are especially grateful to Diego Schleser, José Díaz Bereterbide, María Victoria Castillo-Videla and Moira Ohaco. A thank also goes for Mónica Muscolino. Cristian Alonso, Fernando Delbianco, and Ignacio Cigliutti provided excellent research assistance. The authors also gratefully acknowledge the financial support of FONCyT (PICT/2588-2010).
} 


\section{Introduction}

This paper analyzes unemployment insurance optimal benefit level versus duration in an informal labor market. Although there is a significant amount of literature on the effects of UI on the behavior of workers, ${ }^{1}$ there is little evidence of the impact of UI on developing countries. There are two main issues that make developing countries especially interesting. First, they are usually characterized by stronger financial frictions and less developed financial markets (Rajan and Zingales 1998), which can make unemployment insurance a particularly important mechanism for providing liquidity to the unemployed. Second, informal jobs, which are quite prevalent in developing countries, impose additional constraints on governmental efforts to provide insurance because such jobs generate unobservable re-employment states, which create an additional source of moral hazard. Specifically, if workers can accept jobs in the informal sector while continuing to receive UI benefits without being detected by the government, a more generous UI system would reduce the incentive to search for a formal job and induce workers to accept informal jobs. In this paper, we show that both liquidity and moral hazard effects are high in Argentina.

In the spirit of the sufficient statistics approach (Chetty 2006), we extend the analysis of Shimer and Werning (2007) with a search model of random wage offers that accounts for both informality and limited UI duration to derive a formula that optimally accounts for the trade-off between the level and duration of UI. As in Shimer and Werning (2007), we find that our formula depends on the behavioral responses of workers in two variables: the finding rate and reservation wages. The former is a measure of the unemployment induced by a more generous UI and relates to the cost of UI. The latter relates to welfare gains for the unemployed because under rather general conditions, the reservation wage is a monetary measure of the welfare of the unemployed. Notably, our formula is invariant to the level of informality, meaning that informality impacts the estimate only indirectly through elasticities and parameters.

To evaluate this formula empirically, we use administrative data for 2005 to 2009 from Argentina, a country in which the labor market is characterized by high informality. We exploit certain discontinuities in eligibility and reforms in 2006 to estimate four main elasticities: the elasticities of unemployment duration to an increase in UI benefits and to an extension of UI eligibility and the elasticities of re-employment wages to the same two changes. We find that although an increase in the level of UI increases both unemployment duration and wages, an extension of UI duration prolongs unemployment but does not significantly improve wages. These results suggest that longer UI duration increases the cost of the transfers without any significant evidence of welfare gains for workers. Thus, the preferable option seems to be a redesign of UI that increases the benefit level but shortens its duration.

\footnotetext{
${ }^{1}$ Many papers analyze the effect of higher benefits on the probability of finding a job (Meyer 1990; Katz and Meyer 1990; Bover et al. 2002; Centeno and Álvaro Novo 2014). Others analyze the effects of longer UI duration (Card and Levine 2000; van Ours and Vodopivec 2006a; Lalive 2008) or assess the impact of both higher levels and increased duration of UI (Lalive et al. 2006). Research on the effects of UI on job quality or re-employment wages is less abundant; although it finds a positive relationship between UI generosity and re-employment wages, this result is weaker and less significant. Examples of this strand of literature are Gangl (2002) and Schmieder, von Wachter, and Bender (2010). Additionally, Centeno (2004), Centeno and Novo (2006), and van Ours and Vodopivec (2006b) analyze the effects of UI on quality indicators, including duration of re-employment job, type of job, and wages.
} 
We use our formula to formally evaluate the welfare effect of that type of UI reform. When we calibrate this formula with our estimated elasticities, we find that increasing benefits and reducing the duration of UI in a budget-balancing manner substantially increases welfare. We conclude that in the context of Argentina, a country characterized by high informality, it would be appropriate to increase UI benefits and reduce UI duration.

We provide several robustness checks to support this conclusion. First, we reproduced all of our estimations for workers in the construction sector to show that the same conclusion applies to these workers. Second, we show that the main conclusion remains the same when we use an alternative source of variation. Specifically, we apply regression discontinuity design on the age of the unemployed to identify the effects of extended UI eligibility. This exercise allows us to conclude that our main observation is true for workers around 45 years of age. Third, we show that our conclusion is invariant to the use of a completely different formula, one that rests on the search effort model and alternative estimations. In particular, we extend Chetty (2008) to account for the trade-off between UI duration and level. This formula requires an estimate of the elasticity of unemployment duration to the provision of liquidity that we associate with changes in severance pay (SP) (Chetty 2008; Card et al. 2007). To that extent, we exploit a reform of SP in 2007 that allows for a difference-in-differences estimation. The estimates and the calibration of the formula confirm our main conclusion. Finally, we show that our conclusion does not change when we apply different methods in the estimation of the elasticity, including local weights with optimal bandwidths and imposing censoring in duration.

Our results and conclusions are strongly connected to the paper of Álvarez Parra and Sánchez (2009). Using a calibrated search model, they analyze the optimal profile of unemployment insurance as in Hopenhayn and Nicolini (1997) when workers can be re-employed at hidden jobs. They show that in a context with informal jobs, UI should be high but short-lived. The intuition is that UI acts as a subsidy to search for a job by compensating for the opportunity costs of searching for a formal job instead of accepting a low-quality informal job. However, given that informal jobs are unobservable to the government, the worker can add income from UI to informal wages. For that reason, UI should be relatively short in duration; otherwise, it would be an incentive to collect both wages and UI transfers, essentially acting as a subsidy to informality. Additionally, UI should initially be high so that it adds value to a formal job by providing some form of insurance in case of displacement, as a sort of entitlement effect.

We also contribute to the growing literature on the sufficient statistics approach, which has been applied extensively to unemployment insurance (Chetty 2008; Gruber 1994; Card et al. 2007; Schmieder et al. 2012a). However, the joint determination of the level and duration of UI is not well developed in this literature.

Thus, our contribution to the literature is twofold. First, we provide UI optimal benefit level versus duration discussion in an informal labor market. Second, we derive sufficient statistics to assess welfare effects of UI optimal benefits in developing countries.

In the next section, we develop a search framework and present our main formula. Section 3 presents the characteristics of the labor market and of UI in Argentina, and Section 4 discusses the data and estimation strategy that exploits these characteristics and reforms. Section 5 presents our main empirical results, employs our estimates for a welfare analysis, and demonstrates the robust- 
ness of our methods and data to support our conclusions. Finally, Section 7 provides concluding remarks.

\section{Model}

Our formulas for welfare gains is based on job search theory. We first present a general setup. Then, we restrict the specification of the model to reproduce the formula in Shimer and Werning (2007) and extend it for the case of limited UI duration. Additionally, in Section 5, we return to this setup to exploit the optimal search effort condition as in Chetty (2008). We provide the derivations in Appendix A.

Consider a risk-averse unemployed worker that must search actively for a job. In particular, he faces a search cost of $\psi(\pi)$ in each period, where $\pi \in(0,1]$ is the search effort. In each period, the unemployed worker receives a wage offer at rate $\pi \lambda$. The wage offer is distributed according to the cumulative distribution function $F$ and can be accepted or rejected by the worker. If accepted, the worker collects wages, $w$, net of taxes, $\tau$, in each period of employment. We consider the case of a constant separation rate, $\delta$, from employment to covered unemployment.

With both a search effort and random wage offers, the solution to the problem of an unemployed worker lies in setting the search effort, $\pi^{*}$, and reservation wage, $w^{*}$, that maximize his utility. Given these policies, his finding rate (the probability of receiving and accepting a wage offer) is $\phi^{*}=\pi^{*} \lambda\left[1-F\left(w^{*}\right)\right]$.

An eligible unemployed worker receives a UI transfer of $b$ units of consumption per unit of time. We consider two cases. In the first case, benefits are provided with no limit in duration, whereas in the second case, we allow benefits to become exhausted. Thus, the worker can be employed, unemployed receiving UI benefits (eligible), or unemployed with no transfer.

We let workers begin their unemployment spell with assets, $a$. We also consider that workers without formal jobs can have access to an income, $y$, that is generated from informal labor. This method of modelling informality is based on the assumptions that workers earning informal labor income search for formal jobs and that although the formal labor market is affected by frictions, the informal market is competitive. These assumptions are common in the literature (Albrecht, Navarro, and Vroman 2010; Charlot, Malherbet, and Ulus 2013; Satchi and Temple 2009; Zenou 2008). In Section 3, we provide empirical data that justify this modelling choice. In any case, our main derivations are robust to more complex means of modelling informality, as shown in Appendix A.3. Importantly, we consider a worker with an informal income to be unemployed because these two employment states are indistinguishable to the government.

The problem of the planner is to set UI and taxes to maximize the welfare of workers at the beginning of their unemployment spell, thereby satisfying the constraint that the policy should be actuarially fair (i.e., all benefits should be financed by future taxes). It is important to note that the government does not observe or control the consumption, search effort or reservation wage of the agent. In this sense, the government must address the moral hazard problem that affects worker decisions whenever the policy is changed.

The UI policy reduces incentives to search through two main mechanisms. First, increasing $b$ reduces the utility gain of getting a job because it increases the consumption of the unemployed. 
Second, an increase in taxes is required to finance higher benefits and longer unemployment spells. This tax increase reduces utility gains by decreasing consumption while employed. A planner that aims to provide the optimal level of UI must address the trade-off between providing insurance and liquidity and generating disincentives to re-employment.

The existence of an informal labor income, $y$, changes this problem in several ways. First, an additional income while unemployed reduces the welfare gain provided by UI, given that informal income is a source of consumption for the unemployed. Second, finding a job implies net income gains of $w-\tau-y-b$ because workers must give up both benefits and informal income when they find a formal job. This imposes a clear threshold on $b$ to maintain income gains at re-employment.

A primary question in practice is how to design UI when informality is prevalent. Specifically, should benefits be lower or should the provision of UI be shorter? This depends on the behavioral response of workers to higher benefits and extended UI eligibility. We exploit search models to formally evaluate this trade-off.

\subsection{Reservation wage}

We now consider the case of random wage offers, as in Shimer and Werning (2007). Unemployed workers receive random wage offers and must decide whether to accept or reject the offer by setting a reservation wage, $w^{*}$, such that the worker is indifferent between being employed at that wage or being unemployed. This is equivalent to a setup in which $\psi()=$.0 (ie. $\pi=1$ ). In this case, the reservation wage characterizes the search process of the unemployed, so that the finding rate is $\phi^{*}=\lambda\left[1-F\left(w^{*}\right)\right]$.

The main intuition of this is that the utility of an unemployed worker is a monotone function of his after-tax reservation wage. Thus, the planners objective would be to maximize the after-tax reservation wage. Planners use this idea to derive an optimality formula:

$$
\frac{\partial w^{*}}{\partial b}-\left(1-\varepsilon_{\phi, b}\right) u=0
$$

where the first term measures the welfare gains of higher benefits and the right-hand side measures its costs, which depend on the unemployment rate, $u$, and the elasticity of the finding rate with respect to benefits, $\varepsilon_{\phi, b}$. Given that we do not observe reservation wages, we use the definition of mean re-employment wages, $\bar{w}=\int_{w^{*}} w d F(w)$, and assume that wage offers are log-normally distributed to change the formula as follows:

$$
\begin{array}{r}
\varepsilon_{w, b} \frac{\bar{w}}{b} \Lambda-\left(1-\varepsilon_{\phi, b}\right) u=0, \\
\Lambda=\frac{\sigma^{2}}{\sigma^{2}-v_{W}} \rho
\end{array}
$$

where $\varepsilon_{w, b}$ is the elasticity of re-employment wages with respect to $b, \rho=\frac{w^{*}}{\bar{w}}$ is an indicator of wage dispersion, and $\Lambda$ rescales this effect. Importantly, $\sigma$ and $v_{W}$ are the variances of wage offers and re-employment wages, respectively. We derive this formula in Appendix A and explain how we approximate the ratio $\Lambda$ in Appendix C.1. 
We analyze the welfare gains of a UI extension in a setup in which we model limited UI duration by considering that in each period, the unemployed worker faces a probability $\gamma$ of UI exhaustion. In this case, the government can provide alternative $(b, \gamma)$ combinations at the same cost (i.e., without changing taxes). We use this to derive the welfare gain of an increase in benefits compensated by a decrease in duration (higher $\gamma$ ). We find that welfare gains depend on the response of re-employment wages to both the level and duration of benefits:

$$
\left(\varepsilon_{w, b}-\varepsilon_{w, B} \frac{B}{D_{B}} \frac{1+B / D \varepsilon_{\phi, B}}{1+D_{B} / D \varepsilon_{\phi, b}}\right) \frac{\bar{w}}{b} \Lambda=0 .
$$

where $B=1 / \gamma$ is the expected UI duration and $D$ and $D_{B}$ are the expected durations of the unemployment spell and the covered unemployment spell, respectively.

The first term shows the welfare gains of increasing the benefits level. The second term in the brackets shows the welfare losses caused by a reduction in UI duration $(\partial w / \partial B>0)$. Notice that if this formula gives a positive value, it would be appropriate to increase the level of UI benefits and reduce UI duration. The higher the ratio $\left|\varepsilon_{w, b} / \varepsilon_{w, B}\right|$, the more likely it is that a positive value occurs. Finally, in the last formula, the fact that wage offers are not observable is less important because the sign of the welfare gain does not depend on the distribution of wages. In other words, the only role of $\Lambda$ is to rescale the result; it does not affect the sign of the result.

Overall, to evaluate the optimality of the trade-off between the level and duration of UI, four elasticities are required: $\varepsilon_{\phi, b}, \varepsilon_{\phi, B}, \varepsilon_{w, b}$ and $\varepsilon_{w, B}$. These represent the responses of unemployed workers to UI level and UI extension in two outcomes of their search behavior: the finding rate and re-employment wages.

Before turning to the empirical estimates of these elasticities, it is important to note that these formulas do not directly depend on informality. In other words, informality can change elasticities ${ }^{2}$ and the unemployment level, among other variables in the formula, but informality itself does not need to be calibrated. This result, which is appropriate for our purposes, has previously been noted in the literature (Chetty 2006).

\section{Informality and unemployment insurance}

\subsection{Informality}

Both long unemployment spells and informality are important characteristics of the labor market in Argentina. In this section, we provide a brief description of these issues. We use information from the Permanent Household Survey (EPH, its acronym in Spanish), which is a short panel that follows each household for one year and covers urban areas of Argentina. Its main purpose is to measure unemployment and other labor market indicators.

After the 2001 crisis, Argentina experienced a very high incidence and duration of unemployment. According to EPH, the unemployment rate was $16.3 \%$ in the third quarter of 2003. Since

\footnotetext{
${ }^{2}$ Through this search model it can be shown that, under certain conditions, informality increases the elasticity of finding rate.
} 
then, the unemployment rate showed a negative pattern, reaching $7.3 \%$ in the fourth quarter of 2008. The data also show that more than $40 \%$ of the unemployed searched for a job for more than one year in 2003. In 2006 to 2008, this proportion decreased to approximately one-third. The high incidence and in particular the long duration of unemployment emphasizes the importance of analyzing UI policy.

In our model, informality is related to all jobs that provide labor income that is unobserved by the government. The EPH allows us to identify when an employee is not contributing to the Social Security system. ${ }^{3}$ Regrettably, there is no information in the survey that allows us to reliably identify informality among the self-employed. In any case, informality among that group is high, meaning that most members of that group receive informal income. ${ }^{4}$ In this paper, we will concentrate primarily on informality among employees and analyze transitions that separate employees from the self-employed. In all cases, the information relates to workers between 25 and 60 years of age.

Column (1) of table 1 reports the composition of the adult population between 2005 and 2007. These data show that only one-third of the sample received formal wages. Also during that period, approximately $38 \%$ of employees did not make any contributions to Social Security and $26 \%$ of employed workers were self-employed. Thus, formal employees represented less than one-half of workers receiving some form of labor income.

The literature has characterized informal workers as young, with low levels of education and with jobs in small firms (Gasparini and Tornaroli 2009). Informal jobs are thus related to lower productivity. Additionally, informal jobs are perceived as lower quality jobs because of the lack of social security benefits and the lower wages earned in those jobs compared with formal jobs. Specifically, the ratio between formal and informal wages is 2.4 during this period.

Informal jobs have much higher turnover compared with formal jobs, for two main reasons. First, because these jobs are not affected by severance pay, layoffs are more easily implemented. Second, because informal jobs are usually of a lower quality than formal jobs, workers prefer to move into formal jobs and frequently quit informal jobs. In this sense, it is important to analyze transitions between these states.

Panel (2) of table 1 summarizes quarterly transition rates between states, including transitions out of the labor force, unemployment, formal jobs, informal jobs and self-employment. The main aspect that we want to emphasize is that inflows and outflows from informality are substantial. In particular, $23.5 \%$ of the unemployed turn to informal jobs after one quarter, whereas $13 \%$ begin self-employed activities and less than $6 \%$ finds a formal jobs. In contrast, once workers are in a formal job, they persist in that state: $92 \%$ of formal employees remain formally employed in the following quarter. Informality is much less persistent: less than $70 \%$ informal workers are still working in informal jobs after one quarter. While transition probability from informal jobs to unemployment is $4.5 \%$, a higher proportion finds formal job (9.5\%). Importantly, the transition rate to formality is higher for informal jobs than for unemployment. High turnover is even more significant among informal workers with low tenure. Finally, it is important to emphasize that $4 \%$

\footnotetext{
${ }^{3}$ This is the method typically used to characterize informality. See Gasparini and Tornaroli (2009).

${ }^{4}$ Based on a specially designed household survey, Contartese, Mazorra, Schachtel, and Schleser (2011) report that approximately $60 \%$ of self-employed workers do not declare their activities or pay contributions.
} 
of workers with formal jobs are found with an informal job in the following quarter, whereas the transition rate to unemployment is only $1 \%$. Thus, both inflows and outflows between formal jobs and informal jobs are higher than the same transitions between formal jobs and unemployment.

Overall, the high transition rates into and out of informality justify the notions that informal labor markets are less affected by frictions and that on-the-job searches are relevant in informal jobs. This is even more apparent when one views self-employment activities as a means of generating informal income. For that reason, many papers in the literature have jointly analyzed frictional formal and competitive informal labor markets (Albrecht, Navarro, and Vroman 2010; Charlot, Malherbet, and Ulus 2013; Satchi and Temple 2009; Zenou 2008). In this paper we follow a related approach.

\subsection{Unemployment Insurance}

UI was introduced in 1991 and is a component of the Argentine social security system. ${ }^{5}$ The program is financed by a 1.5 percent payroll tax on employers and is managed by both the Ministry of Labor and the National Social Security Administration (ANSES).

Eligibility requires that workers are laid off from their jobs due to no fault of their own. The program covers all private sector employees except rural workers, domestic workers, school teachers, and university professors. Public sector employees are also excluded. Construction workers were incorporated into the UI system in January 2001. For those who qualify in terms of their sector of activity, eligibility also requires that they are not receiving a pension, workfare benefits, or workers' compensation benefits and that they have contributed to the program during at least 6 out of the last 36 months. These monthly contributions can be either continuous or discontinuous.

Workers receive a monthly benefit starting the month immediately following dismissal, with the exception of construction workers, whose access to benefits starts two months after dismissal. Workers are eligible for 2 to 18 months of support, depending on age, the type of labor contract they had, the sector of activity in which they worked and the number of months that they contributed to the system before dismissal, as shown in Table 2. ${ }^{6}$ The rules in panel A apply to all eligible workers in sectors other than construction who had an indefinite contract (who we will denote as "permanent workers") and who have contributed to the system for 6 or more months during the last 36 months. The rules in panel B apply to construction workers who have contributed to the system for 8 or more months during the last 24 months.

The monthly benefit received by the worker is equal to one-half of his highest salary during the last 6 months of employment, subject to minimum and maximum thresholds established by the National Council of Employment, Productivity and Minimum Wage. Because the maximum threshold is set quite low, most beneficiaries receive that amount. Benefits also decrease over time. Beneficiaries receive the full amount of UI during the first 4 months, $85 \%$ of the full amount during months 5 to 8 and $70 \%$ of the full amount from 9 to 18 months. ${ }^{7}$

\footnotetext{
${ }^{5}$ This section draws heavily on González-Rozada, Ronconi and Ruffo (2011).

${ }^{6}$ In this paper, we concentrate on permanent contracts and report whether the results hold for construction workers as a robustness check. We do not analyze other types of contracts (such as temporary or seasonal contracts), which represent less than $1 \%$ of UI beneficiaries.

${ }^{7}$ UI beneficiaries receive not only the cash transfer described above but also health insurance and family al-
} 
In March 2006, the National Council of Employment, Productivity and Minimum Wage increased the minimum and maximum thresholds of the UI benefit. Before March 2006, the thresholds were Argentinian pesos (ARS) 150 and 300 (50 and 100 US dollars, respectively); after that date, they were ARS 250 and 400 (83 and 133 US dollars, respectively). This increase brought the ratio of UI to mean wages above $25 \%$. It is important to emphasize that this reform did not affect the benefits of workers with pre-unemployment wages above ARS 600, for whom the threshold was not binding.

In the same month, a second reform related to eligibility requirements was introduced. Before March 2006, only workers with at least 12 months of contributions during the last 36 months were eligible. Since March 2006, the prerequisite is less stringent, requiring only 6 months of contributions during the last 36 months for workers who had indefinite contracts.

\section{Estimation strategy and Data}

In this section, we describe our empirical strategy to identify the effects of the UI on job search outcomes. Our identification strategy is based on exploiting the time and cross-sectional variations in the UI benefits described above. This strategy relates to a particular branch of literature that has focused on analyzing UI reforms. Examples of studies in this area include Schmieder, von Wachter, and Bender (2010), Lalive, Ours, and Zweimller (2006) and Card, Chetty, and Weber (2007), among others.

\subsection{Identification}

\subsubsection{Time variation: increase in UI transfers}

As explained in Section 3, there was a sharp increase in the level of UI benefits in April 2006, amounting to approximately $30 \%$ of the benefits thresholds unrelated to labor market conditions; at the time of the increase, the unemployment rate was in a continuous downward trend and job creation and destruction were steady. The reform was prompted by the need to update the minimum and maximum UI benefit levels. High inflation in prices and wages after the $2001 \mathrm{crisis}^{8}$ generated a progressive decline in replacement rates, forcing the government to increase these maximum and minimum thresholds, which finally occurred in March 2006.

We use this significant change in UI level to measure its impact on unemployment duration and wages. We obtain this measurement by analyzing the outcome variables before and after the increase in benefits.

lowances. Health insurance is provided by the same company (usually a labor union) that covered the worker while employed. Family allowances provide the following monetary benefits: a lump sum per child born, per child adopted, and marriage; a monthly transfer per child and per child with disabilities; and an annual transfer per child attending school.

${ }^{8}$ Between 1991 and 2001, the average annual inflation rate in Argentina was 4\%; after the 2001 crisis, in 2002 and 2003, this figure grew to approximately 20\% per year. During the recovery years, in 2004 and 2005, the annual inflation rate was back in the single digits, $7 \%$ on average. 
Additionally, using a difference-in-differences method, we analyze the effect of the UI change on those for whom the UI threshold is binding (those that received ARS 300 of benefits because pre-unemployment wages were higher than ARS 600), using those with lower benefits (for whom benefits did not change) as a control group.

\subsubsection{Cross sectional variation: eligibility for UI benefits}

Our strategy for identifying the effect of longer UI duration exploits two independent and sharp discontinuities in the eligibility requirements for different unemployment insurance schemes. First, workers older than 45 years of age benefitted from a six-month extension of UI. This extension affects all displaced workers eligible for UI, with no exceptions, after July 2006. ${ }^{9}$ Second, the extension of UI jumps at particular numbers of past contributions. For example, young permanent workers with 12 to 23 months of contributions during the last three years are eligible for 4 months of UI, whereas workers with 24 contributions during the same time period are entitled to 8 months of UI benefits. Jumps also occur at 12 and 36 contributions; see Table 2 . We use the second discontinuity in our main application and leave the first discontinuity as a robustness check.

It is important to emphasize that we consider these jumps valid for regression discontinuity analysis. First, for both eligibility conditions, the potential duration of UI changes with probability one, which allows for a sharp analysis. Second, this change can be directly observed in the database, which provides the total number of transfers for which the individual is eligible. Third, the eligibility conditions are implemented automatically and neither the agency nor the worker can change the running variable (i.e., age or number of contributions). In this sense, there is no chance of manipulation. Moreover, it is implausible that these changes in eligibility conditions could modify separations from firms.

We performed a series of tests to analyze the regression discontinuity assumptions. In the first set of tests, we analyze whether covariates jump at the cutoff point to ensure that there are no confounding factors in the estimation of the effect (i.e., to ensure that worker characteristics do not change discontinuously at the cutoff value) and we do not reject the null of no discontinuity. Second, we ensure that UI duration changes discontinuously at the cutoff point (see Figures 1, 2 and 5). Third, following McCrary (2008), we analyze the density of the distribution to ensure that it does not jump at the cutoff points and find no evidence of manipulation in the running variable. Finally, as a robustness check, we analyze the regression discontinuity estimates for alternative cutoff points and find that the effect disappears or loses significance.

For our empirical analysis, we are implicitly assuming that all variables (including age and the number of past contributions) continuously affect outcome variables. Thus, in the regressions, we include a quadratic function of the running variable whereas the effect of an extension of UI is captured by a dummy variable. It is important to emphasize that we include other variables as controls, which means that any remaining differences in covariates on both sides of the threshold are controlled for in our estimates (see Card, Chetty, and Weber (2007) for a similar approach).

\footnotetext{
${ }^{9}$ Although this extension was initially implemented in 2002, it applied only to workers with children attending school, children less than six years old, or children with disabilities until July 2006.
} 


\subsection{Empirical models}

\subsubsection{Unemployment duration}

The first outcome is the impact of UI on the duration of unemployment. Consider the following Cox proportional hazard model of the duration of unemployment:

$$
\theta\left(t_{u} \mid x\right)=\lambda\left(t_{u}\right) \exp (x \beta+y \gamma)
$$

where $\theta$ is the hazard at $t_{u}$ unemployment duration and $\lambda\left(t_{u}\right)$ is the baseline hazard (the exit probability from unemployment to employment) that can take any form. ${ }^{10}$ Covariates, $x$, include polynomials for age, tenure, pre-unemployment wage and the number of pre-unemployment contributions, as well as a series of dummies for gender, occupation and industry of past employment, among other variables. Policy variables, $y$, are defined to exploit sharp changes in UI parameters. In this sense, and depending on the particular exercise, we use indicator variables to identify workers eligible for the UI extension and employ time dummies to identify the periods in which the UI changed. ${ }^{11}$ In particular, when applying regression discontinuity design methods we allow for the marginal effect of the running variable to change at both sides of the cutoff. Thus, we interact the polynomial of the running variable with the treatment variable. We estimate proportional hazard models using these interactions:

$$
\theta\left(t_{u} \mid x\right)=\lambda\left(t_{u}\right) \exp \left(E \gamma+z \beta_{1}+z^{2} \beta_{2}+E\left(z-z^{*}\right) \beta_{3}+E\left(z-z^{*}\right)^{2} \beta_{4}+x \beta_{0}\right)
$$

where $E=I\left(z \geq z^{*}\right)$ is an indicator of extended UI eligibility, $z$ is the running variable (i.e. contributions or age), $z^{*}$ is the cutoff, and $x$ are a set of controls. The coefficient of interest is $\gamma$.

\subsubsection{Reemployment wages}

The other relevant outcome of the search process of the unemployed is the quality of re-employment jobs. Unemployment insurance can simultaneously cause a reduction in the finding rate (which is costly) and improve the matching quality of re-employment jobs (which is an indicator of welfare gains for the unemployed). In this paper, we concentrate on re-employment wages.

The estimation of re-employment wages is analyzed through OLS regression analysis of reemployment wages. Let us consider the following regression model:

$$
\log \left(w_{i}\right)=\alpha+x_{i} \beta+y_{i} \gamma+\epsilon_{i}
$$

where $\log \left(w_{i}\right)$ is the log of re-employment wages, which will be the mean of the wages during the first year at the new job. In this case, we use one observation per spell and select only workers for whom we observe the re-employment job (non-censored spells). As in the previous case, we have

\footnotetext{
${ }^{10}$ Transitions to inactivity will be censored spells because we are not able to identify these cases in the administrative data.

${ }^{11}$ This estimation strategy is related to both Card, Chetty, and Weber (2007) and Lalive, Ours, and Zweimller (2006).
} 
covariates, $x$, that include polynomials on age, tenure and number of pre-unemployment contributions and dummies for gender, occupation and industry of past employment, among others. We also add a quadratic for the total duration of unemployment as an additional control. In regression discontinuity analysis we use the interaction between the running variable and the treatment variable:

$$
\log \left(w_{i}\right)=\alpha+E \gamma+z \beta_{1}+z^{2} \beta_{2}+E\left(z-z^{*}\right) \beta_{3}+E\left(z-z^{*}\right)^{2} \beta_{4}+x \beta_{0}
$$

\subsection{Data}

Our analysis is based on a newly constructed database that combines several sources of administrative information. These sources are (i) the employment records by firm in the Social Security system ("Sistema Integrado Previsional Argentino", the SIPA database); (ii) the monthly payments of independent workers to the Social Security system (the Self-employed database); and (iii) the monthly transfers to beneficiaries of the UI system (the Unemployment Beneficiaries Database, UBd). All of these data have two types of identification numbers: CUIL, which identifies the worker, and CUIT, which identifies the firm. Using CUIL numbers, we were able to combine the databases and follow the same worker through the different situations: wage earner, self-employed and UI beneficiary. ${ }^{12}$

By combining all of these sources, we were able to generate a database for duration analysis. This database, the Administrative Unemployment Duration database (AUD), follows each spell of covered unemployment and gathers information about the workers most recent job, preunemployment work history and re-employment job. We computed the duration of each spell as the difference in months between the period of the layoff and the period in which we first observe the worker as reemployed (either as a wage earner or self-employed). ${ }^{13}$ Using all of the administrative sources, variables for worker characteristics were constructed, providing information such as age, gender, number of children, marital status, etc. We concentrate on beneficiaries of UI in 2005 through 2007. Several reforms were implemented during this period, whereas economic prospects and job creation were quite stable.

Table 3 summarizes the main characteristics of the observations in the database. The workers in our database are predominantly young males who earn relatively low wages. On average, workers are eligible for approximately 9 months of UI.

\footnotetext{
${ }^{12}$ In Appendix B, we briefly describe each administrative dataset used.

${ }^{13}$ The database captures self-employed workers that pay contributions to social security. To contribute, each worker must declare himself to be self-employed and state his type of activity and range of income, which implies a given contribution amount. The information that we used in this paper is restricted to the existence of a contribution in a given period for each worker in our database. We do not use declared income data because we are aware of substantially under-reported income and because the precise level of income is not reported (rather, a wide range of income is declared). In 2006, there were approximately 1.1 million monthly contributions from the self-employed and approximately 5.1 million wage earners were declared by firms. For a more detailed description of data in the SIPA database regarding self-employment and transitions to and from formal jobs, see Ruffo (2011).
} 


\section{Results}

We now turn to the empirical results based on our data, which comprise all UI beneficiaries laid off between 2005 and 2007 and re-employment jobs through 2009. Importantly, to simplify the presentation, we concentrate here on permanent workers.

\subsection{Duration analysis}

\subsubsection{Extension of UI duration}

As explained in Section 3, UI duration depends on the number of contributions in the 36 months preceding the layoff. Notably, UI duration changes in a non-continuous way, jumping at a particular number of contributions (see Table 2). In this exercise, we exploit this discontinuity in duration to estimate the effect of UI duration on different age groups. The analysis by age is relevant because the incentives for re-employment and UI effects differ between young and old workers. For example, Michelacci and Ruffo (2015) study the effects of life cycle aspects on the provision of UI and observe that young workers are less affected by moral hazard than older workers, suggesting that benefits should differ between the young and the old.

In Figures 1 and 2, we show several aspects of the discontinuity that we exploit. First, in panel (a), we show that eligibility for UI duration jumps discontinuously at the cutoff (12 contributions in Figure 1 and 24 contributions in Figure 2), which provides the main identification source for our analysis. Second, in panel (b), we show that mean actual unemployment duration jumps at the cutoff, providing preliminary non-parametric evidence of the effect of UI eligibility on unemployment duration. We confirm with the Wald estimate that the difference at both sides of the cutoff is statistically significant. (Notice that this plot includes both censored and uncensored observations. This issue is corrected below through a proportional hazard model.) In panel (c) we analyze the effect of the extension of UI on re-employment wages. Third, in panels (d) and (e), we show two examples that test the continuity of covariates. We plot pre-unemployment wages and pre-unemployment tenure and find no significant jump of these variables at the cutoff points. We perform a similar analysis with other variables and reach the same conclusion. Finally, panel (f) shows the density and its smoothing to show that there is no evidence of jump at the threshold. We thus, interpret this as evidence of no manipulation of the running variable (McCrary 2008).

To estimate the effect of an extension of UI on finding rates, we run a Cox duration model on an indicator variable that identifies workers who are eligible for the extension of UI (for example, a variable that is zero for workers who are eligible for 4 months of UI and one for workers who are eligible for 8 months of UI, constructed using the indicator function $I($ UI duration $=8)$ ). We control for the quadratic function of the number of past contributions and an interaction between this function and the treatment variable as in equation (4). For purposes of estimating this model, we restrict the sample to workers displaced after the 2006 reform.

Table 4 shows the estimated effect of the extension of unemployment according to the number of past contributions and age. In the first column, we present the estimated effect on permanent workers who had accumulated between 7 and 16 contributions in the 36 months preceding the layoff and were less than 45 years of age at the beginning of the spell. Those with fewer than 12 
contributions would be eligible for 2 months of UI, and those with 12 or more contributions would be eligible for 4 months of UI. We find that the extension of UI duration reduces the finding rate by $21 \%(\exp (-0.24)-1)$. When we consider older workers, we find that the effect is much higher (33\%), which is notable because the extension in that case is from 8 to 10 months, implying that UI extensions have a greater impact on older workers.

Column (3) of Table 4 represents the subsample of young workers that accumulated between 19 and 28 contributions in the 36 months preceding the layoff. We find that the extension from 4 to 8 months of UI reduces the finding rate by almost $40 \%$ for young workers; the impact of an extension of UI from 10 to 14 months for old workers is even greater $(44 \%) .{ }^{14}$

\subsubsection{Higher UI transfers}

We now turn to the estimated effect of benefits level on unemployment duration. For this estimate, we exploit the UI reform in 2006. As explained in Section 3, UI transfers experienced a significant increase in April 2006. Mean and median transfers increased by 30\%, whereas mean private formal wages rose by $3 \%$ between January and July of 2006. Additionally, as emphasized earlier, no changes in macroeconomic conditions occurred during this period. In this sense, the change in UI level can be considered as exogenous: it was based not on recent economic development but rather on the fact that UI amounts had not been updated since the 1990s. Updates in UI are only sporadically implemented; for example, there has been no change in UI from 2006 to 2015.

Figure 3 shows the evolution of the ratio between maximum benefits and mean private wages. Note that these are aggregate variables, independent of the composition of unemployed workers. The change in April 2006 implies a much higher UI transfer. Given the trend of rising wages, the potential impact of higher maximum benefits is reduced. For this reason, we concentrate our analysis around the change: in the estimation of the duration model, we consider displacements between July 2005 and December 2006.

Figure 4 shows the survival functions, comparing UI spells that begin before and after the change. More concretely, we restrict the sample to unemployment spells that begin after a separation between April and June 2005, before the change, and unemployment spells that begin between April and June 2006, after the change. The differences are apparent after eight months of duration. For the pre-change sample, $75 \%$ of workers did not find a job in the first 8 months of unemployment; for the post-change sample, $79 \%$ of workers remained unemployed. The differences amplify for longer durations.

We now turn to the impact estimates using a Cox duration model. First, we estimate the impact of the rise in UI transfers using only an identification variable that is one for periods after April 2006 and zero otherwise ( $I(t>$ March 2006)). We control for a quadratic function of time and an interaction between this function and the treatment variable as in equation (4). In our estimation, we consider the subsample of workers with more than one year of past contributions to avoid any change in the characteristics of UI recipients that would affect the analysis. In particular, we want to avoid any change in the composition of unemployed workers after the reform in March 2006. After that period, workers with between 6 and 11 contributions in the last three years are eligible

\footnotetext{
${ }^{14}$ The effects are quantitatively very similar when measured for the construction workers, but are less precisely estimated.
} 
to receive transfers (two months for workers younger than 45 years of age and 8 months for older workers). This change is important and increases the number of UI recipients.

Using this sample, we find that the increase in benefits reduces the finding rate for both young and older workers but neither of these effects are statistically significant. (See Table 5.) The results show that the increase in UI transfer levels reduces the finding rate, with an elasticity between 0.17 to -0.26 . Thus, an increase in the UI level of $10 \%$ would lead to a 1.7 to $2.6 \%$ reduction in the finding rate. When we impose censoring at 8 months, the estimates of the effect of higher benefits on duration do not change substantially. ${ }^{15}$

\subsection{Impact on re-employment wages}

\subsubsection{Extension of the UI duration}

As explained in Section 4, we apply the same identification strategy presented above, using OLS regressions as in equation (5). In particular, we use the UI duration defined by past contributions. For that purpose, we regress the log re-employment wages on a dummy variable that identifies workers with extended UI benefits, controlling for past contributions with a quadratic function and its interaction with the treatment variable, and including additional controls. As in the duration analysis, we restrict the sample to workers around a given cutoff. For example, in the first column of Table 6, we consider young workers who contributed between 7 and 16 months in the previous 3 years. We find that the effect of extending UI duration from 2 to 4 months significantly increases re-employment wages by $10 \%$. For older workers, this effect seems to be higher but not statistically significant. We then analyze the effects of extending UI for workers who contributed between 19 and 28 months in the last 3 years and find no statistically significant effect on wages for younger or older workers.

\subsubsection{Higher UI transfers}

Finally, we consider the effects of higher UI transfers on re-employment wages. We estimate the impact of the increase in UI transfers using only an identification variable that equals one for periods after April 2006 and equals zero otherwise ( $I(t>$ March 2006)). We control for the quadratic function of time and its interaction with the treatment variable.

Table 7 shows the results of an OLS model of wages on these variables and controls. We find from these estimations that an increase in UI transfers improves the re-employment wages of young permanent workers by approximately $15 \%$. This effect is significant. The effect on workers older than 45 years is around $21 \%$ and is significant too.

\footnotetext{
${ }^{15}$ As a robustness check, we also performed a difference-in-differences analysis. Given that replacement rates were unaffected, the only impact of the increase in UI level is on workers for which the maximum threshold of UI was binding. Exploiting this fact, we use workers with pre-unemployment wages between ARS 500 and 600 as a control group and consider the effect of the change in UI thresholds on workers with wages between ARS 800 and 1,200. The first group was not affected by the change in UI or by the change in minimum and maximum thresholds. The second group changed their UI benefit from ARS 300 to 400 . We find that the effect is $-13 \%$ for young permanent workers and $-17 \%$ for old permanent workers.
} 


\subsection{Welfare implications}

In the previous section, we presented our estimates, providing evidence of the response of workers to changes in UI level and duration. Elasticities of finding rates with respect to UI level are relatively high compared with estimates from other countries, which is reasonable because we observe only formal re-employment and because UI implies higher incentives to search for informal jobs, thus inducing a higher response to UI level. This relates to the observation that under high informality, the moral hazard effect is stronger. The responses of finding rates to UI extensions are also very large, mostly for older workers. Specifically, extending benefits for older workers causes an increase in unemployment duration of the same proportion. This observation highlights the importance of moral hazard.

We also find important responses by re-employment wages, some of which are measured precisely. In particular, wages increase strongly in response to an increase in UI level, with an elasticity of approximately 0.46 for young and 0.6 for older workers. In contrast, the elasticities of wages with respect to an extension of UI are much lower (around 0.1) or lack precision.

Combining these results implies that an increase in UI level has a greater impact on wages compared with an extension of UI. This suggests that a higher UI level generates higher welfare gains. In addition, an increase in UI level has a smaller impact than a UI extension on unemployment duration. This implies that an increase in UI level creates a smaller additional burden on the budget.

Although these estimates are suggestive by themselves, a model is required for a more conclusive analysis about the welfare gains from a policy reform. Using our formulas from Section 2 we analyze the optimality of UI reforms, particularly with respect to the suitability of a higher but shorter UI. We present the calibration of these formulas in the end of this Section. We now illustrate those results considering young workers.

First, we calibrate equation (1). For doing so, we need to plug in into the formula estimated elasticities and parameter values:

$\frac{\widehat{d \ln w}}{d \ln b} \frac{1}{\frac{b}{\bar{w}}} \Lambda-\left(1-\frac{\widehat{d \ln \phi}}{d \ln b}\right) u=\frac{\exp (.14)-1}{0.33} \times \frac{1}{0.27} \times 1.26-\left(1-\frac{\exp (-.06)-1}{0.33}\right) \times 0.29 \simeq 1.8$

The first equation reproduces our formula and shows how we rescale our coefficients $\widehat{(d \ln w}$ and $\widehat{d \ln \phi}$ ) to represent the elasticities in light of the $33 \%$ increase in benefits. The second equation plugs in the numbers of coefficients and parameters. Based on the finding and separation rates that we compute in our dataset, the replacement rate is 0.27 and the unemployment rate is $0.29 .{ }^{16}$ This value is reproduced in line (2) of Table 14. At the end of this section we discuss this result along with the ones that arise from other important estimations. Table 14 also shows the formula calibrated for old workers, who have an unemployment rate of $13 \%$ and a replacement rate of $26 \%$, we find that the calibrated formula is above 2 for them. Since both values, for young and old

\footnotetext{
${ }^{16}$ We use the steady state unemployment rate, $u=\delta /(\phi+\delta)$, and compute the mean finding $\phi$ and separation $\delta$ rates using our databases. See table 13 and Appendix $C$ for a description of the parameters of these formulas.
} 
workers, are positive, this calibration shows that it would be appropriate to increase benefits (for a given duration) and to finance this increase with taxes.

We now calibrate equation (3), which requires some additional elasticities and parameter values. We concentrate first on young workers with between 19 and 28 contributions.

$$
\begin{aligned}
&\left(\frac{\widehat{d \ln w}}{d \ln b}-\frac{\widehat{d \ln w}}{d \ln B} \frac{B}{D_{B}} \frac{1+B / D \frac{\widehat{d \ln \phi}}{d \ln B}}{1+D_{B} / D \frac{\widehat{d \ln \phi}}{d \ln b}}\right) \frac{\Lambda}{\frac{b}{\bar{w}}}= \\
&\left(\frac{\exp (.14)-1}{0.33}-\frac{\exp (.02)-1}{0.69} \times \frac{4}{3.04} \times \frac{1+4 / 24.9 \times \frac{\exp (-.49)-1}{0.69}}{1+3.04 / 24.9 \times \frac{\exp (-.06)-1}{0.33}}\right) \times \frac{1.26}{0.27} \simeq 1.95
\end{aligned}
$$

Through this calibration, we confirm that welfare would increase if benefits were increased at the expense of a reduction in benefit duration. This welfare gain is even higher than the gain financed by taxes. The same outcome occurs when we calibrate the formula for older workers; welfare gains are both positive and high. The welfare gains computed in Table 14 in line (4) are also a calibration for this same formula for different groups. In that table we weight workers with 7 to 16 contributions and workers with 19 to 28 contributions by the proportion of workers in each group to provide only one measure by age group.

We conclude based on our empirical test of the trade-off between UI level and duration that welfare would increase with larger transfers and a shorter duration.

\section{Extensions}

We now present a number of robustness exercises to show that this conclusion does not change if we analyze a different discontinuity in eligibility, or change the strategy more deeply by using a different model and alternative estimates.

\subsection{Extension of UI duration for older workers}

As explained in Section 3, workers older than 45 years of age are eligible for a six-month extension of benefits. Thus, our robustness check uses this discontinuity to analyze the impact of a UI extension.

The main assumption behind the analysis is that any effect of age on the finding rate would be continuous and can be controlled by a function of age. The discontinuous effect at age 45 would capture the extension of UI. In Figure 5, we show that the discontinuity in UI duration eligibility is relevant at the thresholds (see panel (a).) Additionally, panel (b) of that figure shows that the actual mean unemployment duration jumps at the thresholds of the running variable. The Wald test rejects the null of equality on both sides of the threshold. In this sense, the non-parametric analysis suggests an important and significant effect of the UI extension. Panel (c) shows that the mean re-employment wage also has some jump at the cutoff. Additionally, we plot the mean 
of pre-unemployment wages and tenure and show that no relevant jump is observed at the cutoff points (see panels (d) and (e)).

For certain variables and smaller bandwidths, we observe somewhat significant jumps at cutoff points. For example, tenure goes up at 45 years of age. Nevertheless, it should be noted that our results also control for any change in these variables by including them as covariates in the regressions.

Finally, regression discontinuity rests on the idea that the cutoff point is exogenous and cannot be manipulated by the agents. A main aspect of the rules we use is that they are applied automatically using data from Social Security records. In particular, this discontinuity is based on date of birth, which cannot be manipulated. For completeness, we follow McCrary (2008) and analyze the distribution of the running variable. The main objective of this analysis is to test whether there is a jump in the distribution of workers in the running variable to account for possible manipulation of the eligibility criteria. The intuition is that if there is some possibility of manipulation of the running variable by the agents, the density would jump at the cutoff point. (Notice that a jump in density does not necessarily imply manipulation, but the lack of a jump excludes it.) In panel (f) of Figure 5, we show the density estimation of the distribution of observations by age and the graphical result of the McCrary test at optimal bandwidths. It is clear from both graphs that there is no jump in the density and thus manipulation can be excluded.

Duration analysis To provide estimates of elasticities, we run a Cox duration model as specified in equation (4). In particular, we use the indicator variable $I$ (Age $\geq 45)$, which is 1 if the worker is eligible for an extension and zero otherwise. The coefficient associated with the indicator variable is the estimate of the impact of UI extension at age 45. We control for a quadratic function of age to capture any continuous effect of age on duration and we include an interaction between the quadratic function of age and the indicator variable. We also include as controls number of children, gender, marital status, the log of previous unemployment wages, the number of pre-unemployment contributions, tenure, tenure squared, and fixed effects for year, region and industry. We restrict the sample to workers between 35 and 55 years of age and to spells that begin after July 2006.

Table 9 presents the results of these estimations. We observe that the finding rate is reduced by $28 \%$ due to the extension of UI benefits for older workers. This effect is significant. We then restrict the sample to workers with less than 17 contributions, trying to analyze the effects for workers for whom the extension is more relevant (i.e., workers for whom UI duration jumps from 2 to 8 months). The results are even stronger: the finding rate decreases by $30 \%$. These results allow us to conclude that a UI extension based on age significantly reduces the finding rate.

Impact on re-employment wages Table 10 presents the results of the estimations that use the discontinuity at age 45 years to identify the effect of an extension of UI on wages. We find that wages tend to increase due to a UI extension. This increase is approximately $5 \%$, but not significant.

A 6-month extension of UI duration would be more substantial for workers with short durations of UI eligibility; for that reason, we restrict the sample to workers with fewer than 17 contributions. The results are stronger, showing an increase in re-employment wages by $10 \%$ for permanent workers, but the estimates have larger standard errors. 
Implications for welfare When we compare the responses of the finding rate and re-employment wages to the extension of UI at age 45 years, we find that the elasticity of finding rate is relatively high (between -.5 and -.6), whereas the elasticity of wages is approximately or below .1. We calibrate our formula 3) with these new estimates. For that purpose, we use a weighted average of the effects of benefit levels on young and old workers as an estimate of the effect of the benefit level at 45 years of age. All of these calibrations yield high-value welfare gains, indicating that for workers at 45 years of age, it would be appropriate to increase the level of transfers and reduce UI duration. We present these calibrations at the end of this section.

\subsection{Moral hazard versus liquidity}

We now turn to a more substantial extension of our analysis. In fact, we present a different exercise that rests on an alternative construct of the search model and on a measure of the "liquidity effect" as the response of the finding rate to a change in assets.

\section{Framework}

We restrict our attention to cases in which $\lambda=1, \delta=0$, and wage offer distribution is degenerate in a unique value, $w$. We are in a Chetty (2008) setup in which labor market frictions are modeled through search effort only.

As in Section 2, let $b$ be the level of UI, $\tau$ be the tax to finance this transfer, $a$ be the level of assets, and $\phi$ be the finding rate. Through a one-period model, it can be shown that $\frac{\partial \phi}{\partial b}=\frac{\partial \phi}{\partial a}+\frac{\partial \phi}{\partial \tau}$; that is, one dollar provided under the condition of being unemployed should have the same effect as one dollar provided unconditionally minus one dollar if the worker is not unemployed. Thus, the total effect of an increase in benefits is equivalent to a provision of liquidity (equal to the first term, $\frac{\partial \phi}{\partial a}$ ) plus the effect of the increase in taxes, the moral hazard effect (equal to the second term, $\frac{\partial \phi}{\partial \tau}$ ). Importantly, the optimal UI level depends on the relative importance of each of these two effects. Chetty (2008) derives an approximation formula for the welfare gain of an increase in UI benefit level in a dynamic model where benefits are provided from period 0 to $B$. The formula depends on the elasticity of the finding rate to benefits and the response of the finding rate to an increase in assets at the beginning of the unemployment spell, as follows:

$$
\begin{aligned}
\frac{u}{1-u} \frac{D_{B}}{D}\left(\frac{L}{1-L}+\frac{\epsilon_{\phi_{0}, b}}{1-u}\right) & =0 \\
L & \equiv B \frac{\partial \phi_{0}}{\partial a_{0}} / \frac{\partial \phi_{0}}{\partial b},
\end{aligned}
$$

where $B$ is the UI duration; $D$ and $D_{B}$ are the expected durations of the unemployment spell and covered unemployment spell, respectively; $u$ is the unemployment rate; and $\epsilon_{\phi_{0}, b}$ is the total elasticity of the finding rate at the beginning of the unemployment spell, $\phi_{0}$, with respect to benefits level $b$, taking into account the effect of an increase in taxes needed to finance the increase in $b$. Finally, the proportion of the liquidity effect in total effect, $L$, is estimated by comparing the effects of the liquidity provision (a change in assets) and the benefit level on the finding rate $\left(\frac{\partial \phi}{\partial a_{0}}\right.$ and $\frac{\partial \phi}{\partial b}$, respectively). 
We now consider the welfare gains from an extension of UI benefits. ${ }^{17}$ Let $E$ be the additional number of periods of UI duration. Let $e$ be the level of benefits provided in this period, so that the ordinary UI provision is the same as setting $e=0$. To analyze the welfare gains of a UI extension, we compute the change in the lifetime value of being unemployed when $e$ increases. We then rescale this result for it to be comparable to one unit of money spent in $b$. As we derive in the Appendix A, the rescaled optimality condition is:

$$
\begin{aligned}
\frac{u}{1-u} \frac{D_{B}}{D}\left(\frac{L_{E}}{1-L_{E}}+\frac{\eta_{\phi, e}}{1-u} \frac{b D_{B}}{p_{0 B} D_{E}}\right) & =0 \\
L_{E} & \equiv p_{0 B} E \frac{\partial \phi_{0}}{\partial a_{0}} / \frac{\partial \phi_{0}}{\partial e}
\end{aligned}
$$

where $\eta_{\phi, e}=\frac{d \phi_{0}}{d e} / \phi_{0}$ is the partial elasticity of finding rate with respect to benefits in the extension periods. Again, the proportion of the liquidity effect, $L_{E}$, is crucial to this assessment. In the calibration of this formula we use $L_{E}=\frac{p_{0 B} b_{B} E}{S} \frac{\varepsilon_{\phi, S}}{b_{B} \eta_{\phi, e}}$, where we identify the liquidity effect through the response of workers to severance pay, $S$, and we take into account the fact that the level of extended benefits would change from zero to $b_{B}$, which is the level of benefits at $B$ (i.e., our estimate in regressions is $b_{B} \eta_{\phi, e}$ ).

\section{Severance Payments}

We now turn to the estimation of the effects of severance payments on unemployment duration. We first briefly describe severance pay in Argentina ${ }^{18}$ and then present our estimation strategy and our results.

Severance payments in Argentina The Argentine labor code establishes that a dismissed permanent worker should receive one monthly salary per year of tenure (or fraction higher than three months) as severance pay. If the worker's salary has changed over time, severance pay must be computed using the highest monthly salary received during the last year of work. Workers are not legally entitled to receive severance pay if they voluntarily leave the firm, retire, or are terminated from their jobs for cause (this is determined by a judge). Workers do not receive severance pay if at the end of the trial period (i.e., the first three months of employment), the employer decides to terminate the relationship. These regulations apply to all permanent workers in the private sector excluding rural, construction and domestic workers. ${ }^{19}$

In February 2002, in response to the economic crisis that Argentina experienced after December 2001, a new law established a one hundred percent increase in severance pay by increasing the benefit to 2 monthly salaries per year of tenure. The law also established that the higher severance benefit applied only to workers who were hired before February 2002. In January 2005, the increment was reduced to 80 percent (i.e., 1.8 monthly salaries per year of tenure), and in November 2005 , it was reduced further, to 1.5 monthly salaries per year of tenure. In December 2004, a new law established that the higher severance level would automatically end when the unemployment

\footnotetext{
${ }^{17}$ In this analysis, we follow Card, Chetty, and Weber (2007).

${ }^{18}$ See González-Rozada, Ronconi and Ruffo (2011) for a complete description of severance pay in Argentina

${ }^{19}$ Construction workers have a specific program related to dismissal, the Fondo de Cese Laboral, which is justified by the high turnover in this sector.
} 
rate decreased below 10 percent. In September 2007, the unemployment rate effectively decreased below than 10 percent; thus, since that date, severance pay has been at its original level, that is, 1 monthly salary per year of tenure.

Identification: eligibility for SP increments The change in 2007 provides a convenient setup for a difference-in-differences research design: workers affected by the increase in severance pay were those hired before February 2002. We thus observe the outcomes before and after the change for workers in the "treatment" and "control" groups, where the first group comprises workers for which SP doubled in February 2002 and the control group comprises all workers whose severance pay remained unchanged. We also control for any continuous effect of tenure on duration.

In this implementation, we use the reduction of the SP multiplier, which changed from 1.5 to 1 in September 2007, as treatment. Thus, we expect a positive coefficient in duration, given that a lower transfer would increase the urgency of quickly finding a job.

One concern is that the reduction in severance pay could have triggered an increase in firm layoff rates, which would change the characteristics of those displaced. Using the same methods employed for regression discontinuity, we found no evidence of a jump in the separation rate in September 2007, both with and without a seasonal adjustment. The layoff rate is also stable or decreasing (see Figure 6). Additionally, we checked whether the characteristics of workers displaced immediately before and after the change in severance pay differ and found no evidence of change in any observable characteristic (age, tenure, pre-unemployment wages, gender, etc.). Because the identification rests on the assumption that both groups of workers (i.e., the "treated" and "control" groups) are affected equally by shocks other than the change in SP, the evidence presented here reassures us that neither group changes in terms of composition or observable characteristics.

Table 11 presents the results of the estimation of the following Cox duration model

$$
\begin{aligned}
\theta\left(t_{u} \mid x\right) & =\lambda\left(t_{u}\right) \exp (y \gamma+x \beta) \\
\text { where } y \gamma & =\gamma_{1} I\left(t_{s} \geq \operatorname{Sep} 2007\right)+\gamma_{2} I\left(t_{i} \leq \text { Feb2002 }\right)+\gamma_{3} I\left(t_{s} \geq \operatorname{Sep} 2007\right) * I\left(t_{i} \leq\right. \text { Feb2002) }
\end{aligned}
$$

where $t_{s}$ is the period in which the separation occurred, $t_{i}$ is the period in which employment started, and $I()$ are indicator functions. The control variables $x$ are the same as in previous estimations. From this analysis, we observe that the reduction of severance pay has a positive impact. In particular, the reduction in severance pay increases the finding rate by approximately $50 \%$. This implies an elasticity of finding rate with respect to liquidity provision higher than -1 . This elasticity is higher than the one of UI level, implying that liquidity effect is potentially high. We discuss the implications of this estimate on welfare by evaluating equations (6) and (7) at the end of this section.

\subsection{Alternative measures of elasticities}

We now describe a number of alternative methods that we implemented for robustness checks. We begin by discussing wage regressions and duration analyses separately to focus afterwards on new estimates generated by local weighting within optimal bandwidths in regression discontinuity designs. 
We use OLS in our wage regressions. Thus, the results could be affected by selection bias. To analyze whether this issue could alter our results, we run Heckman models in which we include variables for worker characteristics (i.e., marital status and number of children) and unemployment duration in the selection equation. We found no difference between our OLS estimates and the estimates using Heckman models. In any case, we prefer the OLS estimates because our intent is to analyze the effect of UI on paid wages, not on wage offers. Our search model directly implies that UI affects wages through changes in reservation wages and not through wage offers.

One concern regarding our duration models could be that the results might be driven by long durations rather than by durations more directly affected by UI. For that reason, we imposed censoring at 12 months and found no important differences. We report a selection of these results below.

The regression discontinuity design usually allows for the marginal effect of the running variable to change at both sides of the cutoff. An alternative approach would be to evaluate the discontinuous effect of changes in UI assuming that the marginal effects of the running variable does not change discontinuously at the cutoff. To see whether our results change with this more parsimonious specification, we eliminate the interaction between the polynomial of the running variable with the treatment variable. Using these estimates do not change our main conclusion about the behavioral response of workers and about the welfare implications of changes in UI. We report the elasticities implied by this specification in Appendix D and we differ the discussion of these results to the end of this section.

Additionally, it is a common practice in regression discontinuity design to use tight bandwidths with local triangular weights centered at the cutoff to estimate the effect of the discontinuity. In our approach, following Card, Chetty, and Weber (2007), we use more global regressions. Thus, one concern might be whether our results could change if we use locally weighted regressions. Following Lee and Lemieux (2010), we use local regressions as complements to check the robustness of our estimations, based on the idea that both local and global approaches have strengths and weaknesses. Thus, we ran wage regressions using robust standard errors and triangular weights around the optimal Imbens-Kalyanaraman bandwidths (Imbens and Kalyanaraman 2012). We also estimated proportional hazard models with censoring at 12 months and robust standard errors, using triangular weights around tights bandwidths. ${ }^{20}$ In both cases, we use different specifications, including the one described above. The conclusions do not change if we use these coefficients in our welfare formulas. Appendix D reports the elasticities and calibrated welfare formulas using the coefficients described here, using both locally weighted regressions and censoring at 12 months. We discuss the welfare implications of these elasticities at the end of this section.

\subsection{Discussion and summary of results}

In Table 12, we present a summary of our empirical findings by presenting the elasticities computed by rescaling the relevant coefficients reported above. We computed a weighted average of elasticities to concentrate on a unique point estimate for each type of worker. Table 12 reports

\footnotetext{
${ }^{20}$ To compute bandwidths, we used a linear model of duration and computed the Imbens-Kalyanaraman bandwidth. We provide results for twice this bandwidth.
} 
elasticities, $\varepsilon$, of the finding rate, $\phi$, and re-employment wages, $w$, with respect to UI level, $b$, UI duration, $B$, and severance pay, $S$.

While the elasticities of unemployment duration with respect to UI level are relatively low compared to estimates from other countries, the elasticities with respect to UI duration are very high. Additionally, the response to severance pay is very strong, implying that liquidity is a crucial driver of the effects of UI. The fact that Argentina has a less developed financial market could explain the high impact of SP on duration. Finally, the elasticity of the extension of benefits is about .7 for the average worker, implying that if UI is extended by $10 \%$, unemployment duration would increase by approximately $7 \%$. Table 12 also reports the response of wages to changes in UI. On the one hand, the elasticity of wages to changes in UI level is high, about .45 for the average worker. On the other hand, the elasticity of wages to UI duration is much lower, below .1 for the average worker.

On the whole, we find that an increment in UI level has a higher effect on wages compared with an extension of UI. We also find that higher UI level has lower impact on finding rates than a comparable extension of UI. This main fact drives our welfare implications, as we explain below. Before turning to the welfare implications of these estimates we want to emphasize that the main fact noted above is maintained in all our robustness exercises described in Section 6.3. In particular, a proportional rise in UI level affects relatively less the finding rate and relatively more the reemployment wage, compared to a proportional extension of UI (see tables D.1 and D.2 in Appendix D).

\section{Summary of the calibration of the formulas}

We now consider the calibration of the formulas. Table 13 reports all parameter values used in the calibration of the formulas. All parameter values represent our best estimates based on the database or on complementary information, when necessary.

Table 14 reports the calibration of formulas for each type of worker. The first line of the table evaluates equation (6) and indicates that increasing benefits by ARS 1 would increase welfare for the average permanent worker by the equivalent of ARS 0.17 increase in monthly wages. The result is different for different types of workers, being higher for younger workers. The second line evaluates the welfare gain of an increase in UI level using the elasticity of wages as in equation (1). We find a much higher value in this case; specifically, a balanced-budget benefits increase of ARS 1 would yield a welfare gain equivalent to an increase in net wages above ARS 1 . According to this method and our calibration, these welfare gains are substantial for all workers but are higher for older workers.

We now discuss the results regarding the impact of extending UI duration on welfare. Line (3) of Table 14 shows the calibration of equation (7). Recall that this formula is rescaled so that it represents an expenditure for extending benefits equivalent to an increase in regular benefits of ARS 1. Thus, the values of line (3) are comparable to those in line (1). The results show that for the average worker, there is only a low welfare gain from an extension of UI. However, for the group of younger workers, the calibration of the formula yields a positive value, suggesting that for young workers, a balanced-budget extension of benefits would generate a welfare gain similar that of ARS 0.28 increase in wages. Even for these workers is better to increase the level than to extend UI, because the welfare gains are higher in line (1) than in line (3). It is important to note 
that these workers have UI durations that are already short (we evaluate changes 2 to 4 months and from 4 to 8 months of UI). Finally, the fourth line in the table evaluates the formula (3). All values of this line are positive, emphasizing that an increase in benefits of ARS 1 compensated by a shorter UI duration increases welfare substantially, in an amount equivalent to an increase in wages above ARS 1.

Thus, our assessment of UI suggests that benefits should be increased. In particular, our estimations show that the increase in benefits implemented in 2006 should have been higher.

We also conclude that benefits should not be extended and that the optimal profile of benefits implies a higher level and shorter duration. This conclusion is based on analysis of both the welfare gain generated by an extension of benefits and a balanced-budget increase in monthly transfers compensated by a reduction in benefits duration. Notably, both approaches lead to the same conclusion. The calibration of the formulas imply that welfare gains of UI reform on these lines are potentially high. Importantly, the formulas used here are derived from optimality conditions and are derivatives of welfare with respect to changes in UI. If evaluated far from the optimal level, as seems to be the case, their value would tend to overestimate the actual welfare gain.

A caveat regarding our results is that in accordance with the literature, the formulas are calibrated using point estimates, some of which are not significantly different from zero and are measured rather imprecisely. However, it is important to recall that we also use a search effort model, and derive welfare formulas that do not rely on wage elasticities. On the contrary, we estimate an alternative measure that exploits SP (lump-sum transfers at the beginning of the unemployment spell) with effects that are high and significant. Also, our main conclusion is maintained when we use the alternative measures of elasticities based on the methods described in Section 6.3. In particular, using these alternative estimates we find welfare gains of increasing UI benefits that are much higher than the ones of extending UI benefits (see Table D.2 in Appendix D). Finally, we reproduced all the estimations of tables 4 to 10 for construction workers. On the one hand, we found that extending UI prolongs unemployment spells of these workers with higher elasticities than for permanent workers. Additionally, the elasticity of re-employment wages with respect to higher benefits is five times higher than the corresponding elasticity with respect to an UI extension. On the other hand, in contrast to permanent workers, we found that an increase in benefits level has a strong effect on finding rates among construction workers. In any case, when calibrating the formulas we get similar conclusions than for permanent workers: equations (1) and (3) give positive values. Overall, our main conclusions are supported by the consistency of the results across methods, samples and estimations.

\section{Conclusions}

Government policies aimed at protecting workers against the risks of unemployment usually entail important trade-offs. For example, although unemployment insurance allows for consumption smoothing in the presence of imperfect financial markets, it can also reduce search efforts and increase the duration of unemployment. The incentive problem is exacerbated in labor markets with large informal sectors, which are common in developing economies because informal jobs are hidden from the government. In this paper, we analyzed unemployment insurance optimal 
benefit level versus duration in an informal labor market. We exploited a number of reforms and discontinuities in Argentine policies for the purpose of estimating the impact of unemployment insurance on unemployment duration and re-employment wages. Our results can be used by policy makers to design a new UI system or reform an existing one.

We find that an extension of UI eligibility significantly and substantially increases unemployment duration but only modestly increases re-employment wages. In contrast, a higher level of UI transfers has a greater impact on re-employment wages and a smaller impact on unemployment duration. Finally, we use changes in severance pay to identify the effect of a lump sum transfer and show that a relevant portion of the total effect of UI is explained by liquidity. With these estimates, we calibrated optimality formulas derived from two different search models. Using this structure, we are able to evaluate the welfare gains from changes in UI policy and to conclude that UI benefits should be higher but relatively short.

Several remarks are necessary to put our estimates and conclusions in context. Our estimates measure the impact of reforms around 2006, when the ratio of benefits over pre-unemployment wages had a median of approximately $30 \%$ in our sample of beneficiaries. Thus, our conclusion suggests that the replacement rate in Argentina could be greater than that ratio. In addition, the literature has shown that UI should change with the business cycle (see, for example, Landais, Michaillat, and Saez (2013) and Schmieder, von Wachter, and Bender (2012b), among others). Importantly, during the 2005-2009 period, Argentina experienced a continuous expansion in private formal jobs (of approximately $7 \%$ per year). UI during recessions should probably be more generous; more research should be conducted to analyze the optimal profile of UI during recessions. The main conclusion is that if Argentina implements a reform of its UI system or a developing country with high informality introduces a new UI system, a short UI duration should be considered. This conclusion is in line with Álvarez Parra and Sánchez (2009), which analyzes the optimal unemployment insurance provision when hidden labor markets are present. The main argument of that paper is that when informality is prevalent, the duration of benefits should be relatively short. The intuition is that long durations of UI benefits distort the decision making of workers, inducing them to accept hidden jobs (of lower quality) to continue receiving benefits while supplementing their incomes with labor wages. For this reason, it is important not only to provide liquidity for the unemployed but also to limit the moral hazard effect that distorts the finding rate and reduces the efforts of the unemployed to search for formal "good" jobs. A simple way of accomplishing this dual goal is to provide short-term UI transfers. 


\section{References}

Albrecht, J., L. Navarro, and S. Vroman (2010). Efficiency in a search and matching model with endogenous participation. Economics Letters 106(1), 48-50.

Álvarez Parra, F. and J. M. Sánchez (2009). Unemployment insurance with a hidden labor market. Journal of Monetary Economics 56(7), 954-967.

Bover, O., M. Arellano, and S. Bentolila (2002). Unemployment duration, benefit duration and the business cycle. Economic Journal 112(479), 223-265.

Card, D., R. Chetty, and A. Weber (2007). Cash-on-hand and competing models of intertemporal behavior: New evidence from the labor market. The Quarterly Journal of Economics 122(4), 1511-1560.

Card, D. and P. B. Levine (2000). Extended benefits and the duration of UI spells: evidence from the New Jersey extended benefit program. Journal of Public Economics 78(1-2), 107-138.

Centeno, M. (2004). The Match Quality Gains from Unemployment Insurance. Journal of Human Resources 39(3).

Centeno, M. and A. Novo (2006). The Impact of Unemployment Insurance on the Job Match Quality: A Quantile Regression Approach. Empirical Economics 31(4), 905-919.

Centeno, M. and Álvaro Novo (2014). Do Low-Wage Workers React Less to Longer Unemployment Benefits? Quasi-Experimental Evidence. Oxford Bulletin of Economics and Statistics 76(2), 185-207. CentenoNovo14

Charlot, O., F. Malherbet, and M. Ulus (2013). Efficiency in a search and matching economy with a competitive informal sector. Economics Letters 118(1), 192-194.

Chetty, R. (2006). A general formula for the optimal level of social insurance. Journal of Public Economics 90(10-11), 1879-1901.

Chetty, R. (2008). Moral hazard versus liquidity and optimal unemployment insurance. Journal of Political Economy 116(2), 173-234.

Contartese, D., X. Mazorra, L. Schachtel, and D. Schleser (2011). Trabajadores Independientes, Mercado laboral e informalidad en Argentina, Chapter La informalidad en el trabajo independiente: Escape o Exclusión?, pp. 97-117. OIT.

Gangl, M. (2002). Unemployment benefits as a search subsidy: New evidence on duration and wage effects of unemployment insurance. Discussion Papers, Research Unit: Labor Market Policy and Employment FS I 02-208, Social Science Research Center Berlin (WZB).

Gasparini, L. and L. Tornaroli (2009). Labor Informality in Latin America and the Caribbean: Patterns and Trends from Household Survey Microdata. Revista Desarrollo y Sociedad .

González-Rozada, M., L. Ronconi, and H. Ruffo (2011). Protecting workers against unemployment in Latin America and the Caribbean: Evidence from Argentina. Technical report, IDB Working Paper No. IDB-WP-268. 
Gruber, J. (1994). The consumption smoothing benefits of unemployment insurance. NBER Working Papers 4750,

Hopenhayn, H. A. and J. P. Nicolini (1997). Optimal unemployment insurance. Journal of Political Economy 105(2), 412-38.

Imbens, G. and K. Kalyanaraman (2012). Optimal Bandwidth Choice for the Regression Discontinuity Estimator. Review of Economic Studies 79(3), 933-959.

Katz, L. F. and B. D. Meyer (1990). The impact of the potential duration of unemployment benefits on the duration of unemployment. Journal of Public Economics 41(1), 45-72.

Lalive, R. (2008). How do extended benefits affect unemployment duration? A regression discontinuity approach. Journal of Econometrics 142(2), 785-806.

Lalive, R., J. V. Ours, and J. Zweimller (2006). How changes in financial incentives affect the duration of unemployment. Review of Economic Studies 73(4), 1009-1038.

Landais, C., P. Michaillat, and E. Saez (2013). Optimal Unemployment Insurance over the Business Cycle. Discussion Papers 1303,

Lee, D. S. and T. Lemieux (2010). Regression Discontinuity Designs in Economics. Journal of Economic Literature 48(2), 281-355.

McCrary, J. (2008). Manipulation of the running variable in the regression discontinuity design: A density test. Journal of Econometrics 142(2), 698-714.

Meyer, B. (1990). Unemployment insurance and unemployment spells. Econometrica 58(4).

Michelacci, C. and H. Ruffo (2015). Optimal life cycle unemployment insurance. American Economic Review 105(2), 816-59.

Rajan, R. G. and L. Zingales (1998). Financial dependence and growth. The American Economic Review 88(3), pp. 559-586.

Ruffo, H. (2011). Trabajadores Independientes, Mercado laboral e informalidad en Argentina, Chapter El trabajo independiente en los registros de la Seguridad Social, pp. 189-235. OIT.

Satchi, M. and J. Temple (2009). Labor Markets and Productivity in Developing Countries. Review of Economic Dynamics 12(1), 183-204.

Schmieder, J. F., T. von Wachter, and S. Bender (2010, February). The effects of unemployment insurance on labor supply and search outcomes: regression discontinuity estimates from Germany. IAB Discussion Paper 201004, Institut fr Arbeitsmarkt- und Berufsforschung (IAB), Nrnberg [Institute for Employment Research, Nuremberg, Germany].

Schmieder, J. F., T. von Wachter, and S. Bender (2012a). The long-term effects of UI extensions on employment. American Economic Review 102(3), 514-19.

Schmieder, J. F., T. von Wachter, and S. Bender (2012b). The Effects of Extended Unemployment Insurance Over the Business Cycle: Evidence from Regression Discontinuity Estimates Over 20 Years. The Quarterly Journal of Economics 127(2), 701-752. 
Shimer, R. and I. Werning (2007). Reservation wages and unemployment insurance. The Quarterly Journal of Economics 122(3), 1145-1185.

van Ours, J. C. and M. Vodopivec (2006a). How Shortening the Potential Duration of Unemployment Benefits Affects the Duration of Unemployment: Evidence from a Natural Experiment. Journal of Labor Economics 24(2), 351-378.

van Ours, J. C. and M. Vodopivec (2006b). Shortening the Potential Duration of Unemployment Benefits Does Not Affect the Quality of Post-Unemployment Jobs: Evidence from a Natural Experiment. IZA Discussion Papers 2171,

Zenou, Y. (2008). Job search and mobility in developing countries. Theory and policy implications. Journal of Development Economics 86(2), 336-355. 


\section{Tables and Figures}

\subsection{Tables}

Table 1: Quarterly transitions - Urban Adult Population

\begin{tabular}{lrrrrrrr}
\hline \hline Labor market status & $\begin{array}{c}\text { (1) Proportion } \\
\text { of weriod } t \text { ) }\end{array}$ & \multicolumn{6}{c}{ (2) Labor market status in period $t+1$} \\
\cline { 3 - 8 } & OLF & U & FE & IE & SE & Total \\
\hline Out of the labor force (OLF) & 20.9 & 78.2 & 5.5 & 1.3 & 8.5 & 6.5 & 100 \\
Unemployed (U) & 4.7 & 28.3 & 29.5 & 5.8 & 23.5 & 12.9 & 100 \\
Formal employees (FE) & 34.1 & 0.9 & 1.0 & 92.1 & 4.0 & 1.9 & 100 \\
Informal employees (IE) & 21.3 & 8.2 & 4.5 & 9.5 & 67.8 & 10.1 & 100 \\
Self-employed (SE) & 19.1 & 7.8 & 2.5 & 3.4 & 12.0 & 74.3 & 100 \\
\hline \hline
\end{tabular}

Source: EPH, panels from 2005 to 2007.

Note: Workers between 25 to 60 years of age in urban Argentina. Panel (1) reports the proportion of workers in each status. Panel (2) reports quarterly transition rates.

Table 2: Unemployment Insurance Eligibility and Duration

\begin{tabular}{cccccc}
\hline \hline \multicolumn{2}{c}{ Panel A: Permanent workers } & \multicolumn{2}{c}{ Panel B: Construction workers } \\
\hline $\begin{array}{c}\text { Months with } \\
\text { contributions to UI } \\
\begin{array}{c}\text { during the last } \\
36 \text { months }\end{array}\end{array}$ & $\begin{array}{c}\text { Months of UI support } \\
\text { if age }<45 \quad \text { if age } \geq 45\end{array}$ & $\begin{array}{c}\text { Months with } \\
\text { contributions to UI } \\
\text { during the last } \\
24 \text { months }\end{array}$ & $\begin{array}{c}\text { Months of UI support } \\
\text { if age }<45 \text { if age } \geq 45\end{array}$ \\
\hline 6 to 11 & 2 & 8 & 8 to 11 & 3 & 9 \\
12 to 23 & 4 & 10 & 12 to 17 & 4 & 10 \\
24 to 35 & 8 & 14 & 18 or more & 8 & 14 \\
36 or more & 12 & 18 & - & - & - \\
\hline \hline
\end{tabular}

Note: Before March 2006, only workers with at least 12 months of contributions during the last 36 months were eligible. 
Table 3: Main characteristics of beneficiaries (mean of variables)

\begin{tabular}{lrrr}
\hline \hline & All & Permanent & Construction \\
\hline Total UI transfer & 429.81 & 410.65 & 488.62 \\
UI basic transfer & 346.60 & 341.03 & 363.71 \\
Family allowance & 83.20 & 69.62 & 124.91 \\
UI duration eligibility & 8.69 & 9.18 & 7.21 \\
Pre-unemployment wage & 1265.00 & 1200.72 & 1462.35 \\
Contributions & 26.42 & 28.13 & 21.17 \\
Age & 35.84 & 35.06 & 38.21 \\
Males (proportion) & 0.76 & 0.68 & 1.00 \\
Spouse (proportion) & 0.55 & 0.52 & 0.64 \\
Children & 0.93 & 0.79 & 1.36 \\
Observations & 207053 & 156182 & 50871 \\
\hline \hline
\end{tabular}

Source: AUD.

Note: Average of variables in the sample. An observation is an unemployment spell. We provide more details in table E.3.

Table 4: Effect of UI duration - Discontinuity in past contributions - Cox duration model

\begin{tabular}{|c|c|c|c|c|}
\hline & \multicolumn{2}{|c|}{ Between 7 to 16 contributions } & \multicolumn{2}{|c|}{ Between 19 to 28 contributions } \\
\hline & $\begin{array}{l}\operatorname{Age}<45 \\
\text { (1) }\end{array}$ & $\begin{array}{l}\text { Age } \geq 45 \\
\text { (2) }\end{array}$ & $\begin{array}{c}\text { Age }<45 \\
\text { (3) }\end{array}$ & $\begin{array}{c}\text { Age } \geq 45 \\
\text { (4) }\end{array}$ \\
\hline UI Extension & $\begin{array}{rl}-0.2408 & * * * * \\
(0.0376) & \end{array}$ & $\begin{array}{rl}-0.3949 & * * * * \\
(0.1351) & \end{array}$ & $\begin{array}{rl}-0.4896 & * * * * \\
(0.0373) & \end{array}$ & $\begin{array}{rl}-0.5813 & * * * \\
(0.1126) & \end{array}$ \\
\hline Number of observations & 12254 & 12627 & 1596 & 1859 \\
\hline
\end{tabular}

Source: AUD

Note: Coefficients are the result of estimating Cox PH models specified in equation (4). Unemployment durations are censored at 24 months. Controls include quadratic polynomials of past contributions interacted with the indicator variable that identifies jumps in UI eligibility. Additional controls are age and its square, number of children, the log of pre-unemployment wage, the log of imputed severance pay received, tenure in months and its square, and indicator variables for gender, marital status, 11 regions, 10 industries, years, and months of the year. Bandwidths are 5 months of contributions at both sides of the cutoff. Numbers in parentheses are robust standard deviations of the coefficients. Statistical significance: * significant at the $10 \%$ level; ** significant at the 5\% level; *** significant at the $1 \%$ level. 


\section{Table 5: Effect of UI transfer level - Cox duration model}

\begin{tabular}{lcc}
\hline \hline & Age $<45$ & Age $\geq 45$ \\
& $(1)$ & $(2)$ \\
\hline $\mathrm{I}(\mathrm{t} \geq$ March 2006) & -0.0586 & -0.0911 \\
& $(0.0805)$ & $(0.1468)$ \\
Number of observations & 49718 & 12668 \\
\hline \hline
\end{tabular}

Source: AUD

Note: Coefficients are the result of estimating Cox PH models of unemployment duration on the indicator variable that identifies those periods after the change in UI transfer level and its interaction with a quadratic function in calendar time as in equation (4). Additional controls are age and its square, number of children, the log of pre-unemployment wage, the log of imputed severance pay received, tenure and its square, the number of past contributions, aggregate variables including creation rate and unemployment rate, and indicator variables for gender, marital status and month of the year. Sample is restricted to workers who were displaced between July 2005 and December 2006 and who had at least 12 months of contributions. Unemployment durations are censored at 24 months. Numbers in parentheses are robust standard deviations of the coefficients. Statistical significance: * significant at the $10 \%$ level; ** significant at the $5 \%$ level; *** significant at the $1 \%$ level.

Table 6: Effect of UI duration on wages - Discontinuity in past contributions - OLS

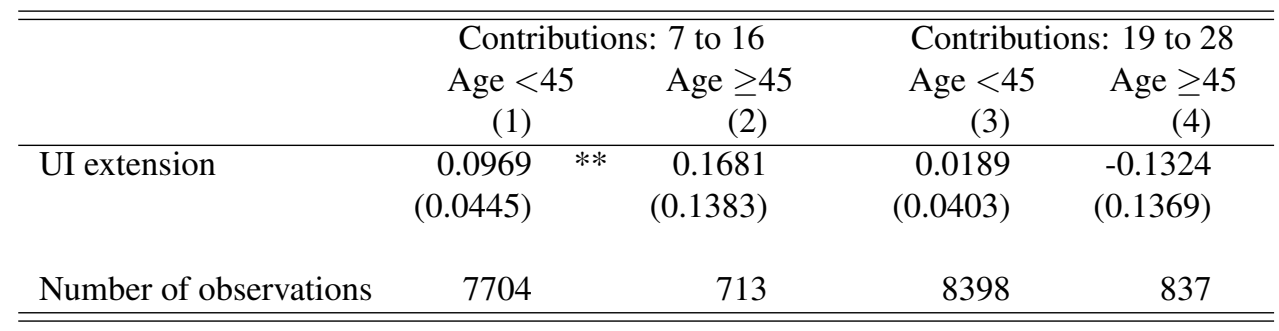

Source: AUD

Note: Coefficients are the result of estimating OLS models of the log of re-employment wage specified in equation (5). Controls include quadratic polynomials of past contributions interacted with the indicator variable that identifies jumps in UI eligibility. Additional controls are age and its square, completed duration and its square, number of children, the log of pre-unemployment wage, the log of imputed severance pay received, tenure, tenure squared, and indicator variables for gender, marital status, 11 regions, 10 industries, years, and months of the year. Bandwidths are 5 months of contributions at both sides of the cutoff. Numbers in parentheses are robust standard deviations of the coefficients. Statistical significance: * significant at the $10 \%$ level; ** significant at the $5 \%$ level; *** significant at the $1 \%$ level. 


\section{Table 7: Effect of UI level on wages - OLS}

\begin{tabular}{|c|c|c|}
\hline & $\begin{array}{c}\text { Age }<45 \\
\text { (1) }\end{array}$ & $\begin{array}{c}\text { Age } \geq 45 \\
\text { (2) }\end{array}$ \\
\hline $\mathrm{I}(\mathrm{t}>\mathrm{March} 2006)$ & $\begin{array}{r}0.1425 \\
(0.0487)\end{array}$ & $\begin{array}{r}0.1945 \\
(0.1075)\end{array}$ \\
\hline Number of observations & 30899 & 5114 \\
\hline
\end{tabular}

Source: AUD.

Note: Coefficients are the result of estimating OLS models of the log of re-employment wage on the indicator variable that identifies those periods after the change in UI transfer level and its interaction with a quadratic function in calendar time as in equation (5). Additional controls are age and its square, completed duration and its square, number of children, the log of pre-unemployment wage, the log of imputed severance pay received, tenure in months and its square, the number of past contributions, aggregate variables including creation rate and unemployment rate, and indicator variables for gender, marital status and month of the year. Sample is restricted to workers who were displaced between July 2005 and December 2006 and who had at least 12 months of contributions. Numbers in parentheses are robust standard deviations of the coefficients. Statistical significance: * significant at the $10 \%$ level; ** significant at the 5\% level; $* * *$ significant at the $1 \%$ level.

Table 8: Effect of UI duration - Discontinuity in past contributions - Cox duration model - Construction workers

\begin{tabular}{|c|c|c|c|c|}
\hline & \multicolumn{2}{|c|}{ Between 8 to 16 contributions } & \multicolumn{2}{|c|}{ Between 13 to 22 contributions } \\
\hline & $\begin{array}{c}\text { Age }<45 \\
\text { (1) }\end{array}$ & $\begin{array}{c}\text { Age } \geq 45 \\
\text { (2) }\end{array}$ & $\begin{array}{c}\text { Age }<45 \\
\text { (3) }\end{array}$ & $\begin{array}{c}\text { Age } \\
(4)\end{array}$ \\
\hline UI extension & $\begin{array}{r}-0.2108 \\
(0.1185)\end{array}$ & $\begin{array}{r}-0.3745 \\
(0.2779)\end{array}$ & $\begin{array}{r}-0.4974 \\
(0.1087)\end{array}$ & $\begin{array}{r}-0.2786 \\
(0.2268)\end{array}$ \\
\hline Number of observations & 7364 & 2353 & 5954 & 2095 \\
\hline
\end{tabular}

Source: AUD.

Note: Coefficients are the result of estimating Cox PH models specified in equation (4). Unemployment durations are censored at 24 months. Controls include quadratic polynomials of past contributions interacted with the indicator variable that identifies jumps in UI eligibility. See table 4 for the description of additional controls. Bandwidths are 5 months of contributions at both sides of the cutoff. Numbers in parentheses are robust standard deviations of the coefficients. Statistical significance: * significant at the $10 \%$ level; ** significant at the $5 \%$ level; *** significant at the $1 \%$ level. 
Table 9: Effect of UI Duration - Discontinuity at 45 years of age - Cox duration model - Workers between 35 and 55 years of age

\begin{tabular}{|c|c|c|}
\hline & \multicolumn{2}{|c|}{ Workers between 35 to 55 years of age } \\
\hline & $\begin{array}{l}\text { All } \\
(1)\end{array}$ & $\begin{array}{l}\text { Less than } 17 \text { contributions } \\
\text { (2) }\end{array}$ \\
\hline $\mathrm{I}(a g e \geq 45)$ & $\begin{array}{r}-0.3234 \\
(0.0377)\end{array}$ & $\begin{array}{r}-0.4689 \\
(0.0883)\end{array}$ \\
\hline Num. of obs. & 33592 & 5095 \\
\hline
\end{tabular}

Source: AUD.

Note: Coefficients are the result of estimating Cox PH models specified in equation (4). Unemployment durations are censored at 24 months. Controls include quadratic polynomials of age interacted with the indicator variable that identifies jumps in UI eligibility. Additional controls are the number of past contributions, number of children, the log of pre-unemployment wage, the log of imputed severance pay received, tenure in months and its square, and indicator variables for gender, marital status, 11 regions, 10 industries, years, and months of the year. Sample is restricted to workers between 35 and 55 years of age, whose displacement was after August 2006. Bandwidths are 10 years of age at both sides of the cutoff. Numbers in parentheses are robust standard deviations of the coefficients. Statistical significance: * significant at the $10 \%$ level; ** significant at the 5\% level; *** significant at the $1 \%$ level.

Table 10: Effect of UI Duration on wages - Discontinuity at 45 years of age - OLS

\begin{tabular}{lrr}
\hline \hline & \multicolumn{2}{c}{ Workers between 35 to 55 years of age } \\
& All & Less than 17 contributions \\
& $(1)$ & $(2)$ \\
\hline $\mathrm{I}(\mathrm{age} \geq 45)$ & 0.0467 & 0.0972 \\
& $(0.0444)$ & $(0.0865)$ \\
& & \\
Num. of obs. & 17359 & 2726 \\
\hline \hline
\end{tabular}

Source: AUD.

Note: Coefficients are the result of estimating OLS models of the log of re-employment wage specified in equation (5). Controls include quadratic polynomials of age interacted with the indicator variable that identifies jumps in UI eligibility. Additional controls are the number of contributions, completed duration and its square, number of children, the log of pre-unemployment wage, the log of imputed severance pay received, tenure and its square and indicator variables for gender, marital status, 11 regions, 10 industries, years, and months of the year. Bandwidths are 10 years of age at both sides of the cutoff. Sample is restricted to workers between 35 and 55 years of age displaced after July 2006. Numbers in parentheses are robust standard deviations of the coefficients. Statistical significance: * significant at the $10 \%$ level; ** significant at the $5 \%$ level; *** significant at the $1 \%$ level. 
Table 11: Effect of SP - Cox duration model

\begin{tabular}{lc}
\hline \hline & Permanent workers \\
\hline I(layoff period $\geq$ Sep 2007)*I $($ entry $<$ Feb 2002) & $0.5161 \quad * * *$ \\
& $(0.0284)$ \\
Number of observations & 247819 \\
\hline \hline
\end{tabular}

Source: AUD.

Note: Coefficient is the result of estimating a Cox PH model specified in equation (9). Unemployment durations are censored at 24 months. Controls include indicator variables I(entry $<$ Feb 2002), that identify those workers for which severance pay can change (those that begun their employment before February 2002), and I(layoff period $\geq$ Sep 2007) those periods of layoffs for which SP changed. Additional controls are age and its square, number of children, the log of pre-unemployment wage, tenure in months and its square, and indicator variables for workers older than 45 years of age, periods after March 2006, gender, marital status, 11 regions, 10 industries, and months of the year. Sample is restricted to permanent workers. Numbers in parentheses are robust standard deviations of the coefficients. Statistical significance: * significant at the $10 \%$ level; $* *$ significant at the $5 \%$ level; *** significant at the $1 \%$ level.

Table 12: Summary of empirical results: elasticities

\begin{tabular}{|c|c|c|c|c|c|c|c|c|}
\hline \multirow{2}{*}{ Finding rate } & \multicolumn{2}{|l|}{$\overline{\text { All }}$} & \multicolumn{2}{|c|}{$<45$ years } & \multicolumn{2}{|c|}{45 years } & \multicolumn{2}{|c|}{$>45$ years } \\
\hline & & & & & & & & \\
\hline \multirow[t]{2}{*}{$\varepsilon_{\phi, b}$} & -0.184 & & -0.173 & & -0.237 & & -0.264 & \\
\hline & $(0.2194)$ & & $(0.2437)$ & & $(0.2974)$ & & $(0.4444)$ & \\
\hline \multirow[t]{2}{*}{$\varepsilon_{\phi, B}$} & -0.584 & $* * *$ & -0.464 & $* * *$ & -0.561 & $* * *$ & -1.388 & $* * *$ \\
\hline & $(0.0368)$ & & $(0.0275)$ & & $(0.0528)$ & & $(0.2143)$ & \\
\hline \multirow[t]{2}{*}{$\varepsilon_{\phi, S}$} & -1.351 & $* * *$ & -1.351 & $* * *$ & -1.351 & $* * *$ & -1.351 & $* * *$ \\
\hline & $(0.0951)$ & & $(0.0951)$ & & $(0.0951)$ & & $(0.0951)$ & \\
\hline \multicolumn{9}{|c|}{ Reemployment wages } \\
\hline \multirow[t]{2}{*}{$\varepsilon_{w, b}$} & 0.488 & $* * *$ & 0.464 & $* * *$ & 0.542 & $* * *$ & 0.651 & $* *$ \\
\hline & $(0.1335)$ & & $(0.1453)$ & & $(0.2839)$ & & $(0.3259)$ & \\
\hline \multirow[t]{2}{*}{$\varepsilon_{w, B}$} & 0.095 & $*$ & 0.084 & $* *$ & 0.107 & $* *$ & 0.166 & \\
\hline & $(0.0656)$ & & $(0.0474)$ & & $(0.0741)$ & & $(0.3918)$ & \\
\hline
\end{tabular}

Notes: Each cell of the table represent an elasticity derived from the results presented in Section 5, by computing the weighted average of different estimates. Total average (all workers) were constructed by averaging results by age, considering the proportion of UI beneficiaries by age. (See Appendix C.1.) Numbers in parentheses are standard deviations. Statistical significance: * significant at the $10 \%$ level; ** significant at the $5 \%$ level; *** significant at the $1 \%$ level. 
Table 13: Parameters for welfare analysis

\begin{tabular}{lrrrr}
\hline \hline & All & $<45$ years & 45 years & $>45$ years \\
\hline Finding rate $(\phi)$ & 0.035 & 0.040 & 0.026 & 0.021 \\
Separation rate $(\delta)$ & 0.010 & 0.015 & 0.009 & 0.005 \\
Unemployment rate $(u)$ & 0.153 & 0.290 & 0.201 & 0.133 \\
Benefit level $(b)$ & 300.0 & 300.0 & 300.0 & 300.0 \\
Benefit level at B $\left(b_{B}\right)$ & 282.0 & 300.0 & 255.0 & 255.0 \\
UI Exhaustion rate $(\gamma)$ & 0.167 & 0.255 & 0.126 & 0.089 \\
UI level/Severance Pay $(b / S)$ & 0.083 & 0.084 & 0.032 & 0.076 \\
Wage inequality $\left(w^{*} / \bar{w}\right)$ & 0.83 & 0.84 & 0.81 & 0.78 \\
Replacement rate $(b / \bar{w})$ & 0.27 & 0.27 & 0.26 & 0.26 \\
Variance adjustment $(\Lambda)$ & 1.50 & 1.50 & 1.50 & 1.50 \\
Duration of benefits $(B)$ & 3.88 & 3.10 & 5.36 & 9.10 \\
Expected duration of benefits $\left(D_{B}\right)$ & 2.93 & 2.45 & 3.45 & 6.17 \\
Duration of UI extension $(E)$ & 3.10 & 3.10 & 6.00 & 3.10 \\
Expected duration of UI extension $\left(D_{E}\right)$ & 2.37 & 2.36 & 3.75 & 2.40 \\
Survival up to B $\left(p_{0, B}\right)$ & 0.76 & 0.78 & 0.58 & 0.62 \\
Unemployment duration $(D)$ & 28.2 & 24.9 & 39.1 & 47.9 \\
\hline \hline
\end{tabular}

Source: AUD.

Note: Each cell in the table represent our best point estimate for the parameter that will be used in the calibration of the formulas. The period is assumed to be a month. See Appendix C.1. 
Table 14: Welfare analysis

\begin{tabular}{|c|c|c|c|c|}
\hline & All & $<45$ years & 45 years & $>45$ years \\
\hline \multicolumn{5}{|l|}{ UI transfer level } \\
\hline (1) Search effort & 0.165 & 0.352 & 0.192 & 0.172 \\
\hline (2) Reservation wage & 2.077 & 1.791 & 2.556 & 2.784 \\
\hline \multicolumn{5}{|l|}{ UI duration } \\
\hline (3) Search effort & 0.041 & 0.276 & 0.004 & -0.029 \\
\hline \multicolumn{5}{|c|}{ Increase in benefits compensated by shorter duration } \\
\hline (4) Reservation wage & 1.710 & 1.659 & 2.058 & 2.042 \\
\hline
\end{tabular}

Note: Each cell in the table represent an indicator of the welfare gain of modifying the UI system.

Line (1) evaluates the equation (6) and line (2) evaluates equation (1).

Line (3) evaluates the equation (7) and line (4) evaluates equation (3).

Elasticities and parameters used in the calibration of these formulas are those reported in tables 12 and 13 . 


\subsection{Figures}

Figure 1: Regression Discontinuity analysis in pre-unemployment contributions (12 contributions)

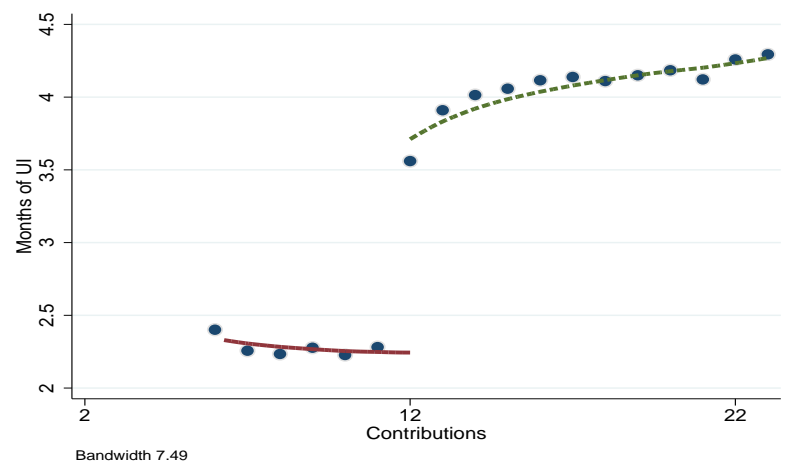

(a) UI dur. eligibility

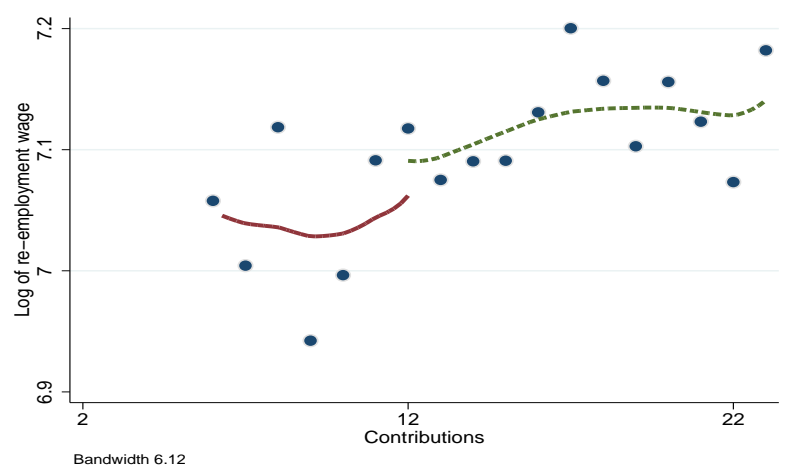

(c) Re-employment wage

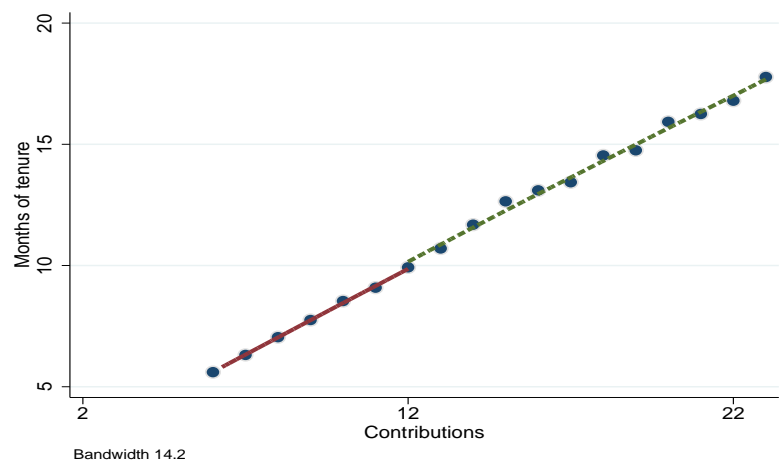

(e) Pre-Unemployment Tenure

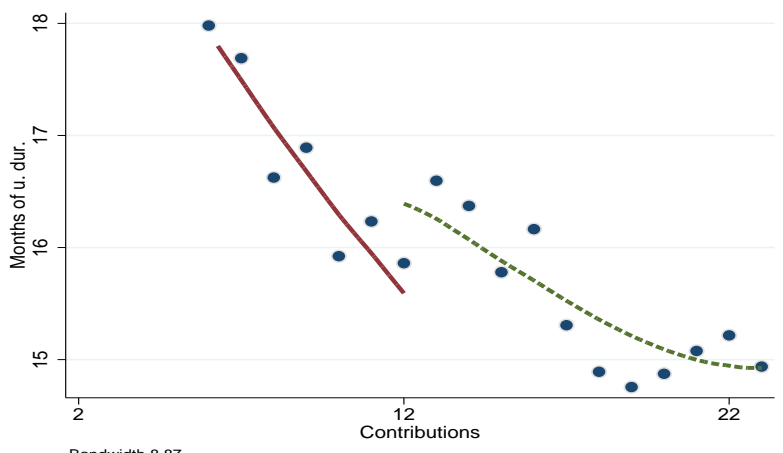

(b) Unemployment Duration

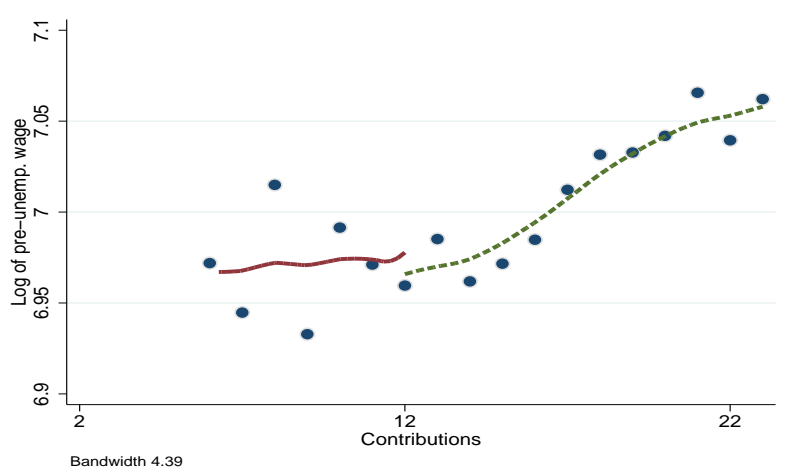

(d) Pre-Unemployment wage

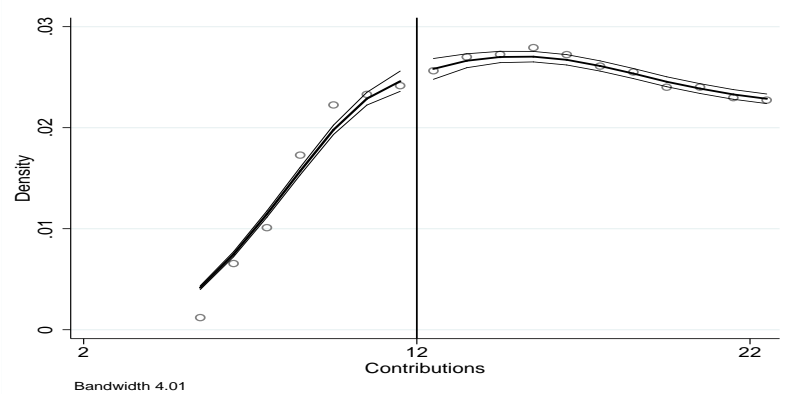

(f) McCrary test

Source: AUD.

Notes: (a) to (e): Regression discontinuity analysis using local linear regressions. Each point in the data is the mean of outcome by past contributions. The sample comprises permanent workers younger than 45 years of age. (f) Density by contributions. 
Figure 2: Regression Discontinuity analysis in pre-unemployment contributions (24 contributions)

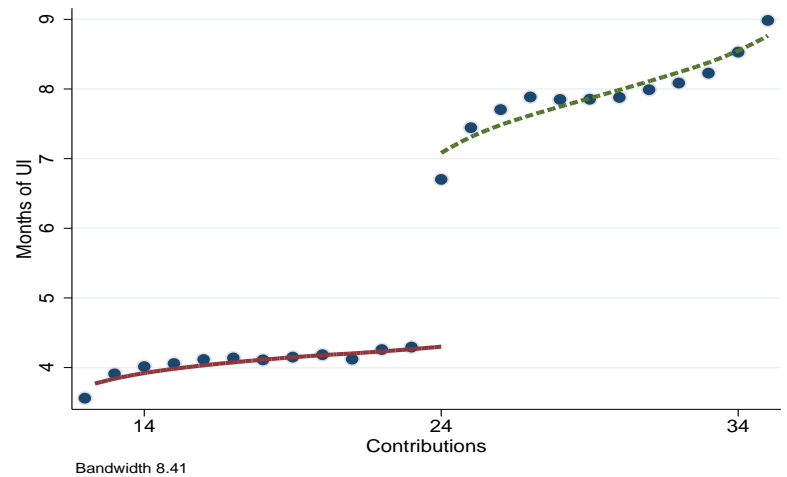

(a) UI dur. eligibility

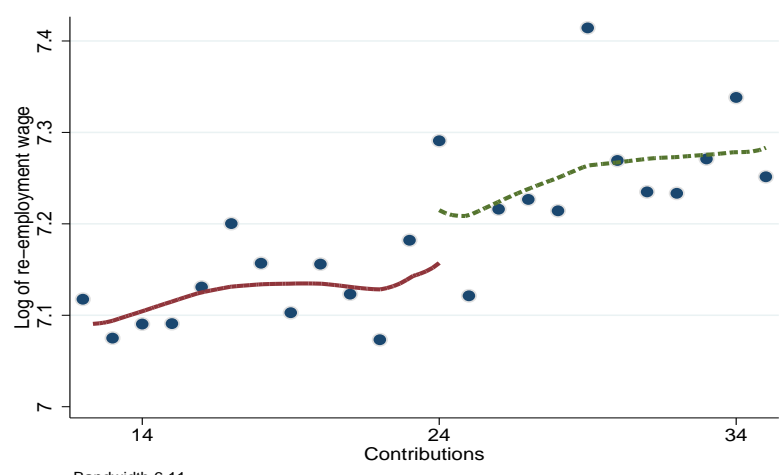

(c) Re-employment wage

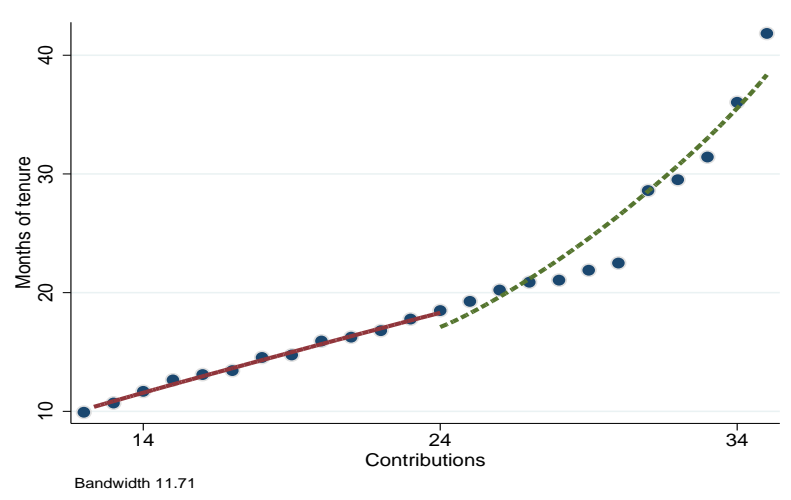

(e) Pre-Unemployment Tenure

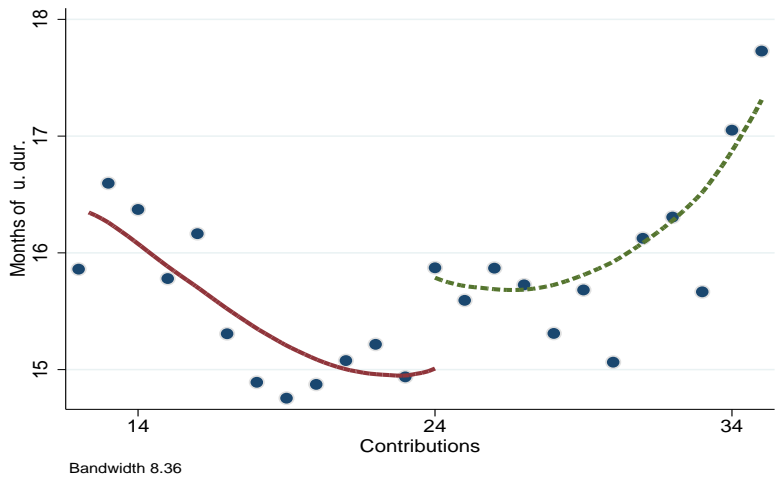

(b) Unemployment Duration

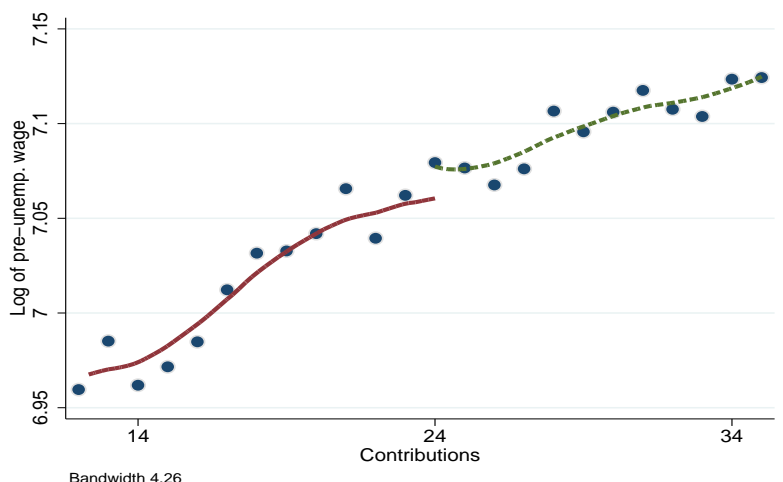

(d) Pre-Unemployment wage

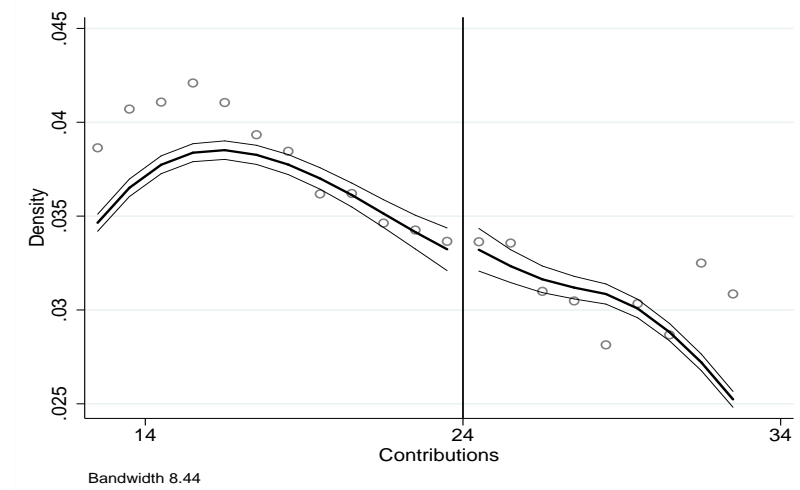

(f) McCrary test

Source: AUD.

Notes: (a) to (e): Regression discontinuity analysis using local linear regressions. Each point in the data is the mean of outcome by past contributions. The sample comprises permanent workers younger than 45 years of age. (f) Density by contributions. 
Figure 3: Maximum benefits over mean private declared wages - 2005 to 2007

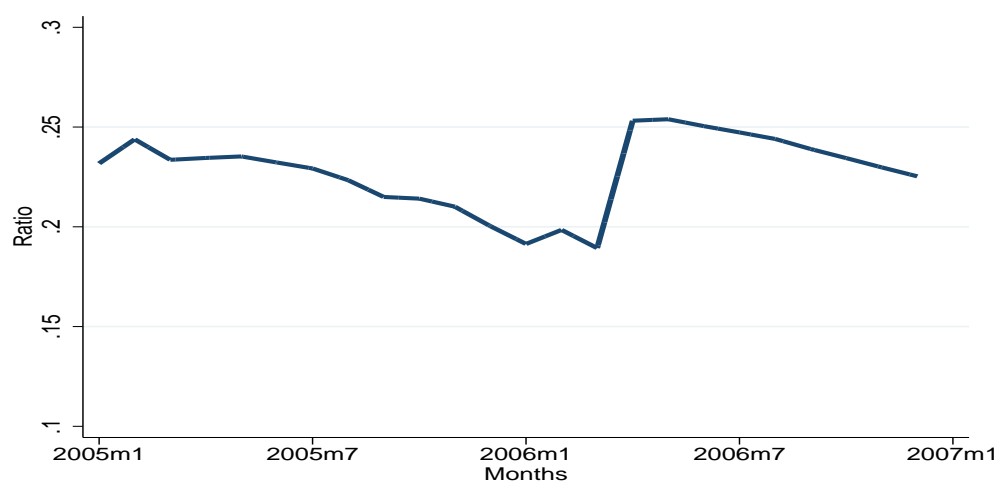

Source: SIPA and UBd.

Figure 4: Effect of UI transfer level - Survival probability and hazard rates before and after the change

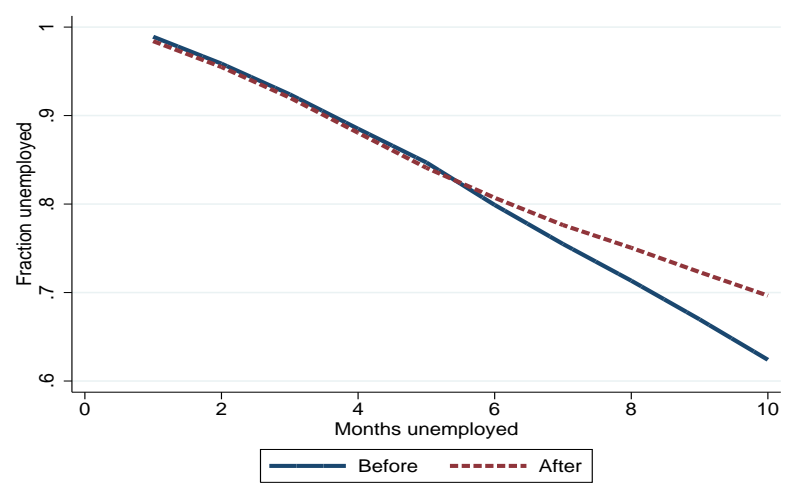

(a) Survival

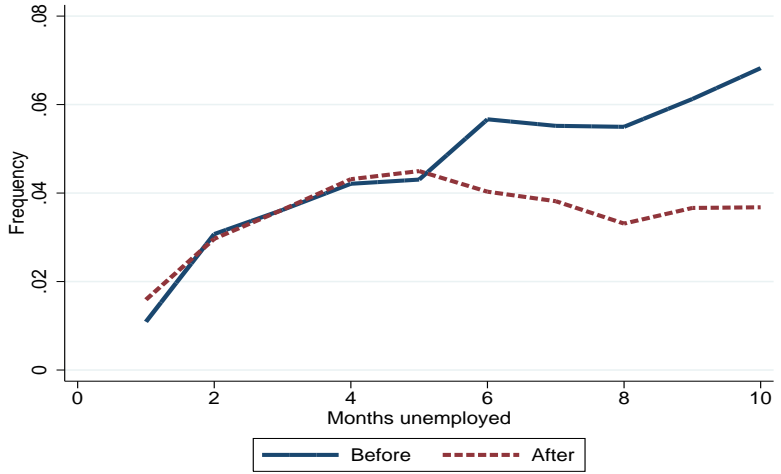

(b) Hazard

Source: AUD.

Note: Survival probability in unemployment before and after the change in UI level of transfers. Sample before change comprises all permanent separations between Apr.2005 and Jun.2005; sample after change comprises all permanent separations between Apr.2006 and Jun.2006. 
Figure 5: Regression Discontinuity analysis in age at displacement

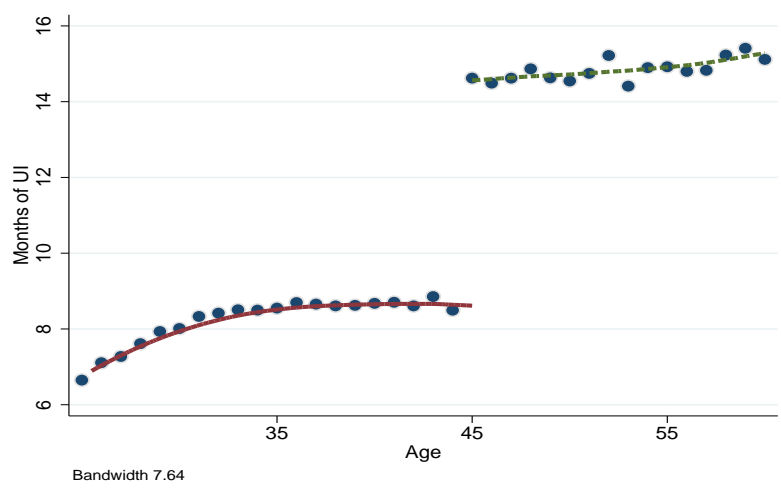

(a) UI dur. eligibility

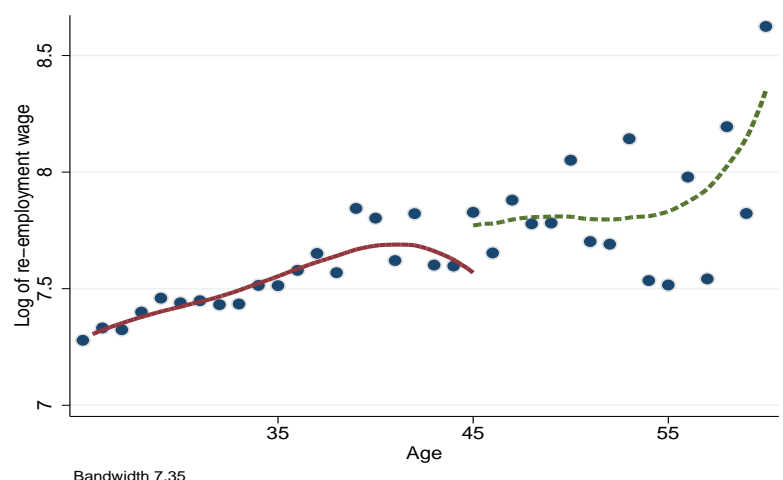

(c) Re-employment wage

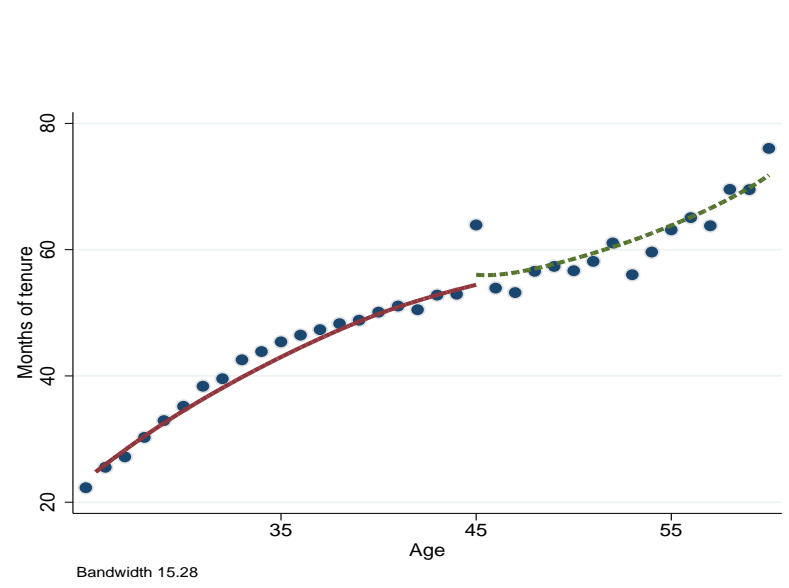

(e) Pre-Unemployment Tenure

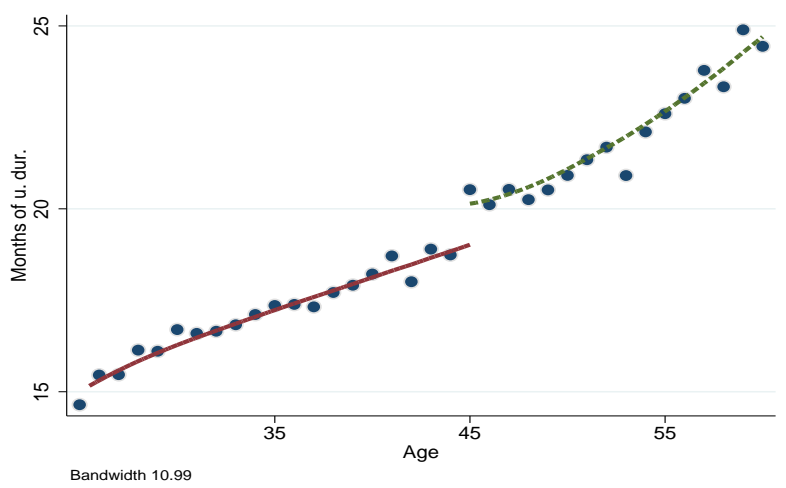

(b) Unemployment Duration

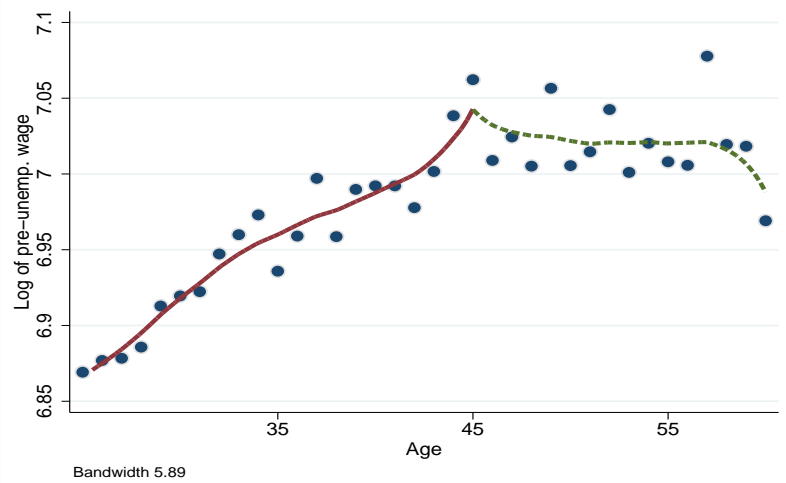

(d) Pre-Unemployment wage

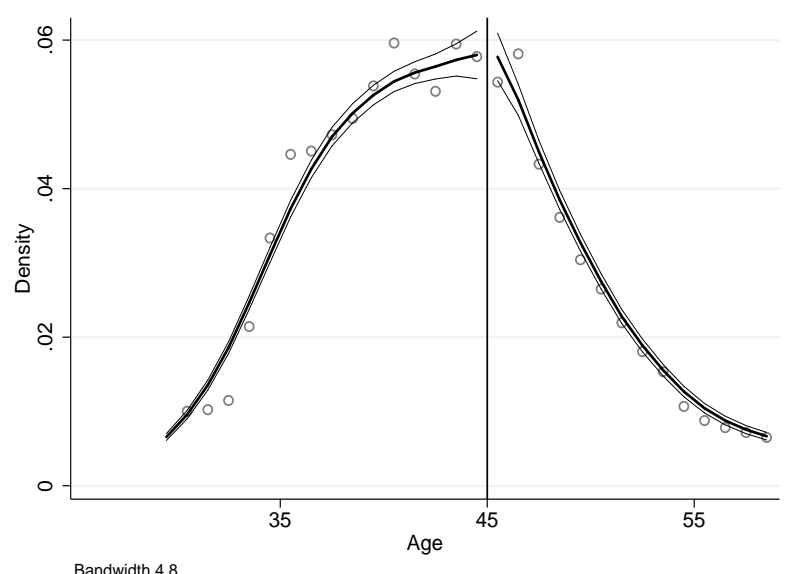

(f) McCrary test

Source: AUD.

Notes: (a) to (e): Regression discontinuity analysis using local linear regressions. Each point in the data is the mean of outcome by age. The sample is restricted to permanent workers. (f) Density by age. 
Figure 6: Separation rate before and after SP change

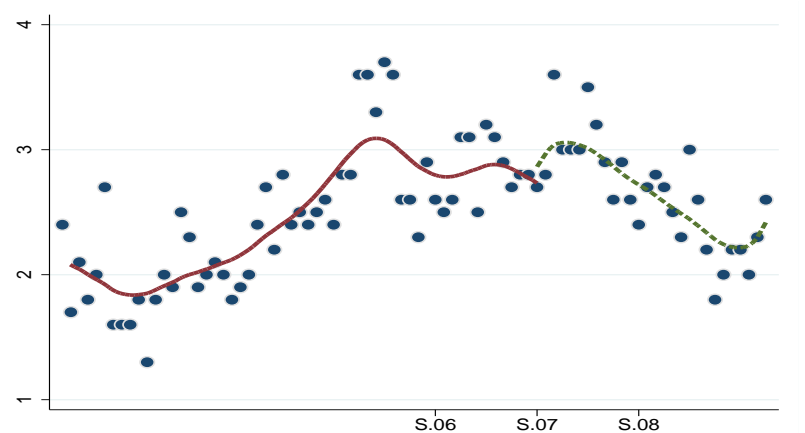

(a) Total Separation Rate

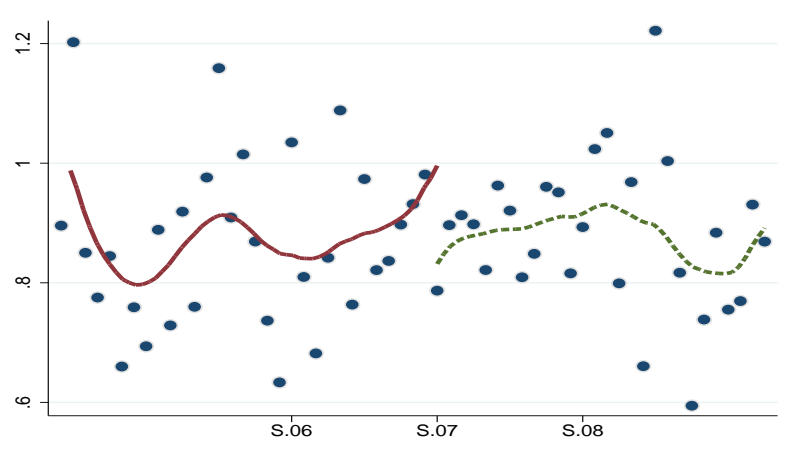

(b) Layoff rate (GBA)

Notes: Regression discontinuity analysis using local linear regressions of separation rate and lay-off rate on time variable. Source: Encueta de Indicadores Laborales. Survey to firms implemented by the Ministry of Labor. Separation rate is the proportion of the workers that separate from the firms in main cities. Lay-off rate is the proportion of workers that are displaced by the firm (excludes quits and temporary contracts) in Greater Buenos Aires. 


\section{Appendix}

\section{A Search models}

\section{A.1 Search effort}

We consider the case in which all jobs pay wage $w>b+y$ and, thus, frictions in the labor market are introduced through search effort. We first consider a one-period search model. The worker solves:

$$
\begin{aligned}
\widetilde{W}(b) & =\max _{\phi}\left\{u\left(c_{u}\right)(1-\phi(b))+u\left(c_{e}\right) \phi(b)-\psi(\phi)\right\} \\
c_{u} & =a(1+r)+b+y \\
c_{e} & =a(1+r)+w-\tau
\end{aligned}
$$

The optimal search effort for the unemployed is then $\psi^{\prime}\left(\phi^{*}\right)=u\left(c_{e}\right)-u\left(c_{u}\right)$. Let us consider shocks to benefits, taxes and assets in period $t$. The change in job finding probability would be

$$
\begin{aligned}
\partial \phi^{*} / \partial b & =-u^{\prime}\left(c_{u}\right) / \psi^{\prime \prime}\left(\phi^{*}\right), \\
\partial \phi^{*} / \partial \tau & =-u^{\prime}\left(c_{e}\right) / \psi^{\prime \prime}\left(\phi^{*}\right), \\
\partial \phi^{*} / \partial a & =\left(u^{\prime}\left(c_{e}\right)-u^{\prime}\left(c_{u}\right)\right) / \psi^{\prime \prime}\left(\phi^{*}\right),
\end{aligned}
$$

respectively. It is clear that $\frac{\partial \phi}{\partial b}=\frac{\partial \phi}{\partial a}+\frac{\partial \phi}{\partial \tau}$ : one dollar provided under the condition of being unemployed should have the same effect as one dollar provided unconditionally minus one dollar if the worker is not unemployed. Thus, the total effect of an increase in benefits is equivalent to a provision of liquidity (equal to the first term, $\frac{\partial \phi}{\partial a}$ ) plus the effect of the increase in taxes, the moral hazard effect (equal to the second term, $\frac{\partial \phi}{\partial \tau}$ ). The latter is a reduction of the incentive to search for a job because benefits reduce the gain that the worker would obtain from a job, this being $w-\tau-b-y$. Notice that both $b$ and $\tau$ tend to increase with more generous UI.

In this setup, the objective of the planner would be to maximize $\widetilde{W}$ subject to the incentive compatibility constraint, $\psi^{\prime}(\phi)=u\left(c_{e}\right)-u\left(c_{u}\right)$, and the budget constraint, $(1-\phi) b_{t}=\tau_{t} \phi$. The impact on welfare of an increase in $b_{t}$ compensated by a rise in $\tau_{t}$ is $\frac{\widetilde{W}}{d b}=(1-\phi) u^{\prime}\left(c_{u}\right)-$ $\phi u^{\prime}\left(c_{e}\right) \frac{d \tau_{t}}{d b_{t}}$.

From the budget constraint, $\frac{d \tau_{t}}{d b_{t}}=\frac{1}{\phi}\left(1-\phi-\epsilon_{\phi, b}\right)$, where $\epsilon$ is the total elasticity of finding rate with respect to changes in benefits (including the effect of taxes). Finally, the welfare gains are

$$
\frac{d \widetilde{W}(a) / d b}{\pi u^{\prime}\left(c_{e}\right)}=\frac{1-\phi}{\phi}\left[\frac{L}{1-L}-\frac{\epsilon_{1-\phi, b}}{\phi}\right]
$$

where $L=\frac{\partial \pi / \partial a}{\partial \pi / \partial b}$ is the relative importance of the liquidity effect and the denominator on the lefthand side is the utility gain of increasing wages so that the equation represents welfare gains in monetary units. 
We now turn to the more general dynamic problem of the search effort when benefits are provided for a limited duration. In this setup, we will consider changes in both the level and duration of UI.

Let $J_{t}$ be the lifetime expected utility of an unemployed worker that begins period $t$ without a job and must actively search for a job in that period with probability $\phi_{t}$ at a utility cost of $\psi\left(\phi_{t}\right)$. Search intensity is chosen by solving

$$
J_{0}\left(a_{0}\right)=\max _{\phi_{0}} \phi_{0} V_{0}\left(a_{0}\right)+\left(1-\phi_{0}\right) U_{0}\left(a_{0}\right)-\psi\left(\phi_{0}\right)
$$

where $V_{0}$ is the lifetime utility value of being employed in period 0 until period $T$ (receiving net wages $w-\tau$ ) and $U_{0}$ is the value of spending that period without a job, collecting unemployment benefits, $b$, and searching for a job at the beginning of the following period. The lifetime utility of a worker collecting UI is

$$
U_{t}\left(a_{t}\right)=\max _{a_{t+1} \in A} u\left(a_{t}-a_{t+1}+m_{t}\right)+J_{t+1}\left(a_{t+1}\right)
$$

where $m_{t}$ is his income while unemployed and the condition $a_{t+1} \in A$ implicitly accounts for the case in which there are liquidity constraints. The value function of being employed is

$$
V_{t}\left(a_{t}\right)=\max _{a_{t+1} \in A} u\left(a_{t}-a_{t+1}+w-\tau\right)+V_{t+1}\left(a_{t+1}\right) .
$$

We assume no discounting in writing these value functions. We assume that unemployment insurance is provided for a limited duration of $B$ periods; we also consider an additional $E$ periods in which the worker receives another type of transfer in the amount of $e$. We will use this additional transfer to analyze the extension of UI benefits by increasing this value from zero. After period $B+E$, no other public transfer is considered. Furthermore, we assume that informal labor income, $y$, can be earned if the worker does not have a formal job. These conditions imply that income for the unemployed is $m=b+y$ up to period $B, m=e+y$ up to period $B+E$, and $m=y$ afterwards.

The problem of the planner would be to maximize $J_{0}$ subject to the budget constraint

$$
\tau(T-D)=b D_{B}+e p_{0 B} D_{E}
$$

where $D$ is the expected duration of the unemployment spell, $D_{B}$ is the expected duration of unemployment benefits, $D_{E}$ is the expected duration of the extension of UI benefits, and $p_{t, i}=$ $\prod_{j=t}^{i}\left(1-\phi_{j}\right)$ is the survival probability in unemployment up to $i$ given survival up to $t$.

Because there is no uncertainty once employed, the worker chooses a constant level of consumption equal to net wages plus the annuity of assets at the beginning of the employment spell. Moreover, following the literature, we will assume that the wealth effect of unemployment duration is mild and that re-employment consumption, $c_{e}$, does not depend on the length of unemployment. Following Chetty (2008), we will define $\left.\frac{\partial z}{\partial x}\right|_{s}=\sum_{t=0}^{s} \frac{\partial z}{\partial x_{t}}$. For $b, \frac{\partial z_{0}}{\partial b}=\left.\frac{\partial z_{0}}{\partial b}\right|_{B}$, because UI lasts for $B$ periods. 


\section{A.1.1 Optimal UI level}

The planner's problem of establishing the optimal level of benefits in fixed duration $B$ entails maximizing

$$
J_{0}=\left(1-\phi_{0}(b, \tau)\right) U_{0}(b, \tau)+\phi_{0} V_{0}(b, \tau)-\psi\left(\phi_{0}(b, \tau)\right)
$$

subject to $\tau(T-D)=b D_{B}$, where we assume for now that there is no UI extension $(e=0) .{ }^{21}$. Thus,

$$
\frac{d J_{0}}{d b}=\left(1-\phi_{0}\right)\left[\frac{\partial U_{0}}{\partial b}-\frac{\partial U_{0}}{\partial w} \frac{d \tau}{d b}\right]-\phi_{0} \frac{\partial V_{0}}{\partial w} \frac{d \tau}{d b}
$$

Given that $\left.\frac{\partial \phi_{0}}{\partial x}\right|_{B}=\frac{1}{\psi^{\prime \prime}\left(s_{0}\right)}\left[\left.\frac{\partial V_{0}}{\partial x}\right|_{B}-\left.\frac{\partial U_{0}}{\partial x}\right|_{B}\right]$ and $\frac{\partial V_{0}}{\partial b}=0$, we obtain $\frac{d J_{0}}{d b}=-\left(1-\phi_{0}\right) \psi^{\prime \prime}\left(\phi_{0}\right) \frac{\partial s_{0}}{\partial b}-$ $\left(1-\phi_{0}\right) \frac{\partial U_{0}}{\partial w} \frac{d \tau}{d b}-\phi_{0} \frac{\partial V_{0}}{\partial w} \frac{d \tau}{d b}$.

Let us consider an increase in welfare due to a $\$ 1$ increase in wages from period 0 . The increase in welfare would be equivalent to $\frac{d J_{0}}{d w}=\left(1-\phi_{0}\right) \frac{\partial U_{0}}{\partial w}+\phi_{0} \frac{\partial V_{0}}{\partial w}=(T-D) v^{\prime}\left(c_{e}\right)$. Thus,

$$
\frac{d W}{d b}=\frac{\frac{d J_{0}}{d b}}{\frac{d J_{0}}{d w}}=-\frac{\left(1-\phi_{0}\right)}{T-D} \frac{\psi^{\prime \prime}\left(\phi_{0}\right)}{v^{\prime}\left(c_{e}\right)} \frac{\partial \phi_{0}}{\partial b}-\frac{d \tau}{d b}
$$

Furthermore, it can be shown that $\frac{\partial \phi_{0}}{\partial w}=\frac{1}{\psi^{\prime \prime}\left(\phi_{0}\right)} \frac{1}{\left(1-\phi_{0}\right)}\left[D v^{\prime}\left(c_{e}\right)\right]$. However, $\frac{d \tau}{d b}=\frac{D_{B}}{T-D}\left(1+\varepsilon_{D_{B}, b}+\varepsilon_{D, b} \frac{D}{T-D}\right)$, and assuming that $\varepsilon_{D_{B}, b}=\varepsilon_{D, b}, \frac{d \tau}{d b}=\frac{D_{B}}{T-D}\left(1+\varepsilon_{D, b} \frac{T}{T-D}\right)$. After replacing these in equation (A.3), we get

$$
\frac{d W}{d b}=\frac{D_{B}}{T-D}\left[-\frac{B \frac{\partial \phi_{0}}{\partial a}}{B \frac{\partial \phi_{0}}{\partial a}-\frac{\partial \phi_{0}}{\partial b}}-\frac{\varepsilon_{D_{B}, b}}{\frac{T-D}{T}}\right]
$$

where we use $\left.\frac{\partial \phi_{0}}{\partial w}\right|_{B}=\frac{1}{\psi^{\prime \prime}} \frac{1}{1-\phi_{0}}\left[D_{B} v^{\prime}\left(c_{e}\right)\right]=\frac{D_{B}}{D} \frac{\partial \phi_{0}}{\partial w}$ and $\frac{\partial \phi_{0}}{\partial b}=\left.\frac{\partial \phi_{0}}{\partial a}\right|_{B}-\left.\frac{\partial \phi_{0}}{\partial w}\right|_{B}$. Finally, following Chetty, we assume that $\left.\frac{\partial \phi_{0}}{\partial a}\right|_{B} \approx B \frac{\partial \phi_{0}}{\partial a}$. To obtain equation (6), we assume that the unemployment rate, $u$, is an approximation of $D / T$, so that

$$
\frac{d W}{d b}=\frac{u}{1-u} \frac{D_{B}}{D}\left(\frac{L}{1-L}+\frac{\epsilon_{\phi_{0}, b}}{1-u}\right),
$$

where $L$ is the proportion of liquidity effect in total effect, $L=B \frac{\partial \phi_{0}}{\partial a_{0}} / \frac{\partial \phi_{0}}{\partial b}$. Notably, the higher the liquidity effect relative to total effect, the higher the welfare gain from an increase in benefits.

\section{A.1.2 Extension of UI benefits}

We now analyze the effect of an extension of UI. We consider increasing the value $e$, which are the benefits paid from period $B$ for $E$ consecutive periods. Consider that

$$
\frac{d J_{0}}{d e}=\left(1-\phi_{0}\right)\left[\frac{\partial U_{0}}{\partial e}-\frac{\partial U_{0}}{\partial w} \frac{d \tau}{d e}\right]-\phi_{0} \frac{\partial V_{0}}{\partial w} \frac{d \tau}{d e}
$$

\footnotetext{
${ }^{21}$ This problem is identical to the one derived in Chetty (2008), and this part closely follows that paper.
} 
Again, $\frac{\partial \phi_{0}}{\partial e}=-\frac{1}{\psi^{\prime \prime}} \frac{\partial U_{0}}{\partial e}$. Additionally, $\frac{d J_{0}}{d w}=\left(1-\phi_{0}\right) \frac{\partial U_{0}}{\partial w}+\phi_{0} \frac{\partial V_{0}}{\partial w}=(T-D) v^{\prime}\left(c_{e}\right)$, and $\frac{\partial \phi_{0}}{\partial w}=\frac{1}{\psi^{\prime \prime}\left(\phi_{0}\right)} \frac{1}{\left(1-\phi_{0}\right)}\left[D v^{\prime}\left(c_{e}\right)\right]$.

However, increasing $e$ in $\$ 1$ not only has a direct effect on $\tau$ of $\frac{p_{0, B} D_{E}}{T-D}$ but also affects both $D$ and $D_{B}$. Thus, $\tau^{\prime}=\frac{D_{B}}{T-D}\left(p_{0, B} \frac{D_{E}}{D_{B}}+\frac{T}{T-D} \eta_{D, e} b\right)$, where we assume that $\eta_{D_{B}, e}=\eta_{D, e}$. Thus,

$$
\frac{d W}{d e}=\frac{d J_{0}}{d e} / \frac{d J_{0}}{d w}=-\frac{D}{T-D} \frac{\frac{\partial \phi_{0}}{\partial e}}{\frac{\partial \phi_{0}}{\partial w}}-\frac{D_{B}}{T-D}\left(p_{0, B} \frac{D_{E}}{D_{B}}+\frac{T}{T-D} \eta_{D, e} b\right),
$$

where we use $\frac{\partial \phi_{0}}{\partial w}=\frac{1}{\psi^{\prime \prime}\left(\phi_{0}\right)} \frac{1}{\left(1-\phi_{0}\right)}\left[D v^{\prime}\left(c_{e}\right)\right]$. Furthermore, $\frac{\partial \phi_{0}}{\partial w_{E}}=\frac{1}{\psi^{\prime \prime}} \frac{1}{1-\phi_{0}}\left[p_{0 B} D_{E} v^{\prime}\left(c_{e}\right)\right]=$ $\frac{p_{0 B} D_{E}}{D} \frac{\partial s_{0}}{\partial w}$. Additionally, we use the equivalence $\frac{\partial \phi_{0}}{\partial e}=\frac{\partial \phi_{0}}{\partial a_{E}}-\frac{\partial \phi_{0}}{\partial w_{E}}$ and assume that $p_{0 B} E \frac{\partial \phi_{0}}{\partial a_{0}}=\frac{\partial \phi_{0}}{\partial a_{B}}$ to get

$$
\frac{d W}{d e}=\frac{D}{T-D} \frac{p_{0 B} D_{E}}{D}\left(\frac{-p_{0 B} E \frac{\partial \phi_{0}}{\partial a_{0}}}{p_{0 B} E \frac{\partial \phi_{0}}{\partial a_{0}}-\frac{\partial \phi_{0}}{\partial e}}-\frac{D_{B}}{p_{0 B} D_{E}} \frac{T}{T-D} \eta_{D, e} b\right) .
$$

By using the approximation $u=D / T$, defining $L_{E}=p_{0 B} E \frac{\partial \phi_{0}}{\partial a_{0}} / \frac{\partial \phi_{0}}{\partial e}$, and assuming that $\eta_{D, e}=$ $-\eta_{\phi, e}$, we have that

$$
\frac{d W}{d e}=\frac{u}{1-u} \frac{p_{0 B} D_{E}}{D}\left(\frac{L_{E}}{1-L_{E}}+\frac{b D_{B}}{p_{0 B} D_{E}} \frac{\eta_{\phi, e}}{1-u}\right) .
$$

Finally, we use the elasticities to obtain $L_{E}=\frac{p_{0 B} E \frac{\phi_{0}}{S} \frac{S}{\phi_{0}} \frac{\partial \phi_{0}}{\partial a_{0}}}{\frac{\phi_{0}}{\phi_{0}} \frac{\partial \phi_{0}}{\partial e}}=\frac{p_{0 B} E \varepsilon_{\phi, S}}{S \eta_{\phi, e}}$. Additionally, our estimate of UI extension is equivalent to $\frac{\partial \phi}{\partial e} \frac{d e}{\phi}=b_{B} \eta_{\phi, e}$. Thus, we calibrate the formula using

$$
\begin{aligned}
\frac{d W}{d e} & =\frac{u}{1-u} \frac{p_{0 B} D_{E}}{D}\left(\frac{L_{E}}{1-L_{E}}+\frac{b}{b_{B}} \frac{D_{B}}{p_{0 B} D_{E}} \frac{b_{B} \eta_{\phi, e}}{1-u}\right), \\
L_{E} & =\frac{p_{0 B} b_{B} E}{S} \frac{\varepsilon_{\phi, S}}{b_{B} \eta_{\phi, e}} .
\end{aligned}
$$

\section{A.2 Reservation wage}

We now analyze a setup in which the unemployed worker faces random wage offers. Any change in policy will affect not only unemployment duration but also mean re-employment wages. Below, we first derive the main formula in Shimer and Werning (2007) and then extend the analysis to derive the welfare gains from changes in UI duration.

Consider a risk-averse worker that discounts the future at rate $r$ and perceives utility as an increasing and concave function $u(c)$, where $c$ represents the instant consumption flow. In each period, the worker can be employed, unemployed receiving UI benefits (eligible) or unemployed with no benefits. An eligible unemployed worker receives a UI transfer of $b$ units of consumption per unit of time. The worker faces a probability $\gamma$ of losing this benefit. Workers without a for- 
mal job have access to $y$ units of consumption from informal labor income. In each instant, the unemployed worker faces a constant probability $\lambda$ of receiving a wage offer from the cumulative distribution function $F$. The worker can choose to accept or reject the wage offer. An employed worker receives $w$ units of consumption per unit of time and pays taxes $\tau$. We assume that the worker can be laid off with an instant probability of $\delta$, in which case he becomes an eligible unemployed. We assume that workers have financial assets, $a$, and have access to a riskless borrowing and lending market that satisfies the standard no-Ponzi condition. At some point, to simplify the derivation, we will also consider the case in which $a=0$ for all periods, i.e., the case of hand-tomouth consumers.

The expected lifetime utility of a worker employed at wage $w$ and with assets $a$, denoted by $V(w, a)$, satisfies

$$
\begin{aligned}
r V(w, a)= & \max _{c}\left(u(c)+\frac{\partial V(w, a)}{\partial a}(r a+w-\tau-c)\right) \\
& +\delta[U(a)-V(w, a)]
\end{aligned}
$$

where $V_{a}$ denotes the derivative of the value function with respect to assets and $U(a)$ is the lifetime utility of an unemployed worker with assets $a$. The latter value satisfies

$$
\begin{aligned}
r U(a)= & \max _{c}\left\{\left(u(c)+U^{\prime}(a)(r a+b+y-c)\right)\right. \\
& \left.+\lambda \int \max \{V(w, a)-U(a), 0\} d F(w)+\gamma[S(a)-U(a)]\right\} .
\end{aligned}
$$

where $U^{\prime}$ denotes the derivative of the value function with respect to assets and $S$ is the lifetime utility of an unemployed after UI exhaustion, which satisfies

$$
\begin{aligned}
r S(a)= & \max _{c,}\left\{\left(u(c)+S^{\prime}(a)(r a+y-c)\right)\right. \\
& \left.+\lambda \int \max \{V(w, a)-S(a), 0\} d F(w)\right\} .
\end{aligned}
$$

The first parenthesis on the right-hand side of these equations represents the intertemporal consumption problem of the worker. The second term in (A.5) and (A.6) describes the gain associated with the receipt of a wage offer, which will be accepted only if the new job is better than being unemployed. Finally, the last term in equation (A.4) measures the loss associated with a layoff, and the last term of equation (A.6) represents the utility loss of UI exhaustion.

The problem for the worker is to set consumption and a reservation wage, $w^{*}$. The consumption decision is governed by an Euler equation. The reservation wage is the solution to

$$
V\left(w^{*}, a\right)=U(a)
$$


Finally, it is appropriate to define $\phi=\lambda\left[1-F\left(w^{*}\right)\right]$ as the finding rate and

$$
\bar{w}=\int_{w^{*}} w d F(w)
$$

as the mean re-employment wage.

\section{A.2.1 The planner's problem}

The problem of the government is to set UI policy and taxes in a manner that maximizes the welfare of the unemployed while satisfying the resource constraint. We restrict the analysis to constant benefit policies of limited duration (such as the one described above). Additionally, we consider the case of hand-to-mouth agents in which reservation wages (and thus $\phi_{u}$ and $\phi_{s}$ ) are constant. Alternatively, as shown by Shimer and Werning, assuming CARA preferences also translates into constant finding rates.

Under an actuarially fair policy, the government budget constraint is

$$
\begin{aligned}
r C & =b+\phi_{u}\left(C_{e}-C\right)+\gamma\left[C_{s}-C\right] \\
r C_{e} & =-\tau+\delta\left[C-C_{e}\right] \\
r C_{s} & =\phi_{s}\left[C_{e}-C_{s}\right]
\end{aligned}
$$

where $C, C_{s}$ and $C_{e}$ are the net present values of the cost of providing the policy for the newly unemployed, non-eligible unemployed and employed workers, respectively. An actuarially fair policy implies $C=0$, so that

$$
b=\phi_{u} \frac{\tau}{r+\delta}+\frac{\gamma \phi_{s}}{r+\phi_{s}} \frac{\tau}{r+\delta} .
$$

In the limit as $r$ converges to zero, this expression becomes

$$
b=\tau \frac{\phi_{u}+\gamma}{\delta}
$$

If we also assume that finding rates are constant and compute steady state unemployment rates, we find that this condition is equivalent to $u b=l \tau$, where $u$ is the proportion of eligible unemployed workers and $l$ is the proportion of employed workers. ${ }^{22}$

The problem for a government that aims to provide unemployment insurance for a worker with assets $a$ entails maximizing $U(a)$ subject to the budget constraint (A.9) and the incentive compatibility constraint defined by equation (A.7).

\section{A.2.2 Optimal UI level}

We will first concentrate on the case in which there is no limit on eligibility, $\gamma=0$. To ease the exposition, we will concentrate on the case of hand-to-mouth workers (whose assets are zero for

\footnotetext{
${ }^{22}$ To see this , consider the law of motion of the proportion of unemployed workers, $\dot{u}=\delta l-\phi_{u} u-\gamma u$. In a steady state, $\dot{u}=0$ and $\delta l=\left(\phi_{u}+\gamma\right) u$.
} 
all periods), but the main features of the derivation apply to workers who have access to financial markets, as in Shimer and Werning. Reservation wage policy, equation (A.7), implies that

$$
r U(0)=u\left(w^{*}-\tau\right)
$$

so that the problem of the government is equivalent to maximizing after-tax reservation wages, $w^{*}-\tau$. The main intuition is that the net reservation wage is a monetary counterpart of the utility of the unemployed. The first order condition for the planner's problem is thus

$$
\frac{\partial w^{*}}{\partial b}+\frac{\partial w^{*}}{\partial \tau} \tau^{\prime}=\tau^{\prime}
$$

To analyze the change in taxes, we consider the budget constraint specified in equation (A.9). Additionally, we follow Shimer and Werning in assuming CARA utility to obtain $\frac{\partial w^{*}}{\partial b}=\frac{\partial w^{*}}{\partial \tau}$ and thus $\frac{\partial \phi}{\partial b}=\frac{\partial \phi}{\partial \tau}$. In this case, $\tau^{\prime}=\frac{\frac{r+\delta}{\phi}-\frac{r+\delta}{\phi} \varepsilon_{\phi, b}}{1+\frac{r+\delta}{\phi} \varepsilon_{\phi, b}}$. To simplify the formula, we focus on the limit as

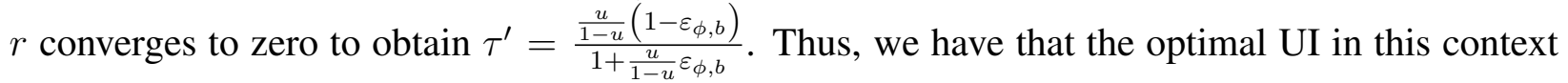
should satisfy

$$
\frac{\partial w^{*}}{\partial b}=\left(1-\varepsilon_{\phi, b}\right) u
$$

\section{A.2.3 Optimal UI duration}

We will now extend the analysis to consider the problem of a limited duration of UI. In this case, the planner should define the level of benefits $(b)$ and the probability that the benefits will be exhausted $(\gamma)$. To analyze this problem, we will consider an increase in $b$ complemented by an increase in $\gamma$ to balance the government's budget (leaving taxes constant). The problem of the planner is to maximize the net reservation wage, $w^{*}-\tau$, subject to (A.9). The first order condition is

$$
\frac{\partial w^{*}}{\partial b}+\frac{\partial w^{*}}{\partial \gamma} \gamma^{\prime}=0
$$

Differentiating the budget constraint and assuming that $r \rightarrow 0$, we get

$$
\gamma^{\prime}=\delta / \tau\left(1-\tau / \delta \frac{\partial \phi_{u}}{\partial b}\right) /\left(1+\frac{\partial \phi_{u}}{\partial \gamma}\right),
$$

which implies that whenever $b$ increases, $\gamma$ should also increase to balance the budget (i.e., the duration of UI is shortened). Next, we use (A.10) and the definition of elasticity $\varepsilon_{\phi, x}=\partial \ln \phi / \partial \ln x$ to get

$$
\frac{\partial w^{*}}{\partial b}+\frac{\partial w^{*}}{\partial \gamma} \frac{1}{D_{B} b} \frac{1-\varepsilon_{\phi_{u}, b} \frac{D_{B}}{D}}{1+\varepsilon_{\phi_{u}, \gamma} \frac{B}{D}}=0,
$$

where we use the approximations $D=\frac{1}{\phi_{u}}, B=\frac{1}{\gamma}$, and $D_{B}=\frac{1}{\phi_{u}+\gamma}$.

The first term of this equation evaluates the welfare loss caused by the reduction of UI duration (notice that $\frac{\partial w^{*}}{\partial \gamma}<0$ ); the second term evaluates the welfare gain generated by an increase in 
benefits that compensates the savings obtained by shortening UI duration. If this equality is satisfied, then the balance between UI level and duration is optimized. If this equation is positive, then welfare would be increased by an increase in benefits compensated by a reduction in UI duration.

\section{A.2.4 From reservation wages to mean wages}

In our empirical analysis, we observe realized accepted wages, whereas reservation wages are unobservable. Concretely, we have estimates of $\frac{\partial \bar{w}}{\partial b}$ rather than $\frac{\partial w^{*}}{\partial b}$. To show how these estimates differ, we use the definition of mean re-employment wages in equation (A.8) and obtain that $\frac{\partial \bar{w}}{\partial b}=$ $\frac{\partial w^{*}}{\partial b} \frac{f\left(w^{*}\right)}{\left[1-F\left(w^{*}\right)\right]}\left[\bar{w}-w^{*}\right]$. Additionally, if we assume that $w$ is normally distributed with mean $\mu$ and variance $\sigma^{2}$, then $v_{w} \equiv \operatorname{Var}\left[w \mid w \geqq w^{*}\right]=\sigma^{2}-\sigma \frac{f\left(\frac{w^{*}-\mu}{\sigma}\right)}{1-F\left(\frac{w^{*}-\mu}{\sigma}\right)}\left[\bar{w}-w^{*}\right]$. Given that $\frac{f\left(\frac{w^{*}-\mu}{\sigma}\right)}{1-F\left(\frac{w^{*}-\mu}{\sigma}\right)} \frac{1}{\sigma}=$ $\frac{f\left(w^{*}\right)}{1-F\left(w^{*}\right)}$, this implies that $\frac{\partial w^{*}}{\partial b}=\frac{\partial \bar{w}}{\partial b} \frac{\sigma^{2}}{\sigma^{2}-v_{w}}$. Notice that the ratio $\frac{\sigma^{2}-v_{w}}{\sigma^{2}}$ is bounded between zero and one. In the case in which $w^{*}=\mu$, the rate equals the hazard of a normal distribution at the mode, $\simeq .6366$ (to see this, simply use the formula for the mean of a truncated normal). An analogous derivation can be used if $w$ is log-normal: $\frac{\partial w^{*}}{\partial b}=\frac{\partial \overline{\log (w)}}{\partial b} w^{*} \frac{\sigma^{2}}{\sigma^{2}-v_{w}}$. Thus, the optimality of UI can be analyzed through

$$
\varepsilon_{w, b} \frac{\bar{w}}{b} \frac{\sigma^{2}}{\sigma^{2}-v_{w}} \rho-\left(1-\varepsilon_{\phi, b}\right) u=0,
$$

where $\varepsilon_{w, b}$ is the elasticity of wages with respect to benefit level, a behavioral response that we estimate, and $\rho$ varies from 1 with the assumption of normal distribution and $\frac{w^{*}}{\bar{w}}$ when wages are lognormal. Additionally, we assume that $\varepsilon_{D, b}=-\varepsilon_{\phi, b}$. We will estimate $v_{w}$ and $\sigma$, the variances of observed and offered wages, respectively, using Heckman selection models for re-employment wages.

Additionally, we use the same condition to rewrite (A.11)

$$
\left(\varepsilon_{w, \gamma} B+\varepsilon_{w, b} D_{B} \frac{1+\frac{\phi_{u}}{\gamma} \varepsilon_{\phi_{u}, \gamma}}{1-\frac{\phi_{u}}{\phi_{u}+\gamma} \varepsilon_{\phi_{u}, b}}\right) \bar{w} \rho \frac{\sigma^{2}}{\sigma^{2}-v_{w}}=0,
$$

where we use $B=1 / \gamma$. Notice that in this case, the wage offer distribution does not affect the sign of the welfare gain: if the term in the brackets is positive, one can conclude that increasing benefits and reducing duration is welfare improving.

\section{A.3 Allowing for transitions into and out of informal jobs}

Our modelling of informality is simple. We implicitly assume that workers can immediately find an informal job, as if the informal labor market was competitive. Modelling a frictional formal labor market and a competitive informal sector is frequent in the literature (Albrecht, Navarro, and Vroman 2010; Charlot, Malherbet, and Ulus 2013; Satchi and Temple 2009; Zenou 2008). This assumption implies that any effect of UI on the formal job finding rate would lead to changes in informality.

We now want to relax these assumptions to show that our formula remains relevant if there 
are transitions between unemployment and informal jobs. First, we will show that the welfare of workers without a formal job is a monotone function of net reservation wages. Second, we explain that the only behavioral response that is relevant to an analysis of the effect of UI on the government budget is the elasticity of the formal job finding rate. Whether workers transition from unemployment or from informal jobs is irrelevant to the government. This observation is related to the extension in Shimer and Werning (2007), which shows that the same formula applies to heterogeneity in worker types.

In this extended model, we suppose that there are transitions from three states: unemployed without additional income (which we call unemployment), unemployed with informal wage income (which we call informal jobs) and employed in formal jobs (or simply employed). Transitions between employment and unemployment are determined by the exogenous parameter $\delta_{0}$, and the analogous transition rate to informality is $\delta_{I}$. Additionally, we suppose that there is a constant transition probability from unemployment to informality, $\gamma_{I}$, whereas the probability of losing that informal income is $\gamma_{0}$. Finally, there is a $\lambda_{0}$ probability that an unemployed worker will receive a formal wage offer; the analogous probability for workers earning informal income is $\lambda_{I}$. To simplify, we assume there is no exhaustion of unemployment insurance $(\gamma=0)$ and no hand-to-mouth workers $(a=0)$.

Under this setup, there are two reservation wages defined by

$$
\begin{aligned}
& r U_{0}=r V\left(w_{0}^{*}\right)=u\left(w_{0}^{*}-\tau\right)+\delta_{I}\left[U_{I}-U_{0}\right], \\
& r U_{I}=r V\left(w_{I}^{*}\right)=u\left(w_{I}^{*}-\tau\right)+\delta_{0}\left[U_{0}-U_{I}\right],
\end{aligned}
$$

where $U_{0}$ is the lifetime utility of the unemployment state and $U_{I}$ is the analogous value of the informal employment state. Solving these equations yields

$$
\begin{aligned}
& r\left(r+\delta_{0}+\delta_{I}\right) U_{0}=\left(r+\delta_{0}\right) u\left(w_{0}^{*}-\tau\right)+\delta_{I} u\left(w_{I}^{*}-\tau\right), \\
& r\left(r+\delta_{0}+\delta_{I}\right) U_{I}=\left(r+\delta_{I}\right) u\left(w_{I}^{*}-\tau\right)+\delta_{0} u\left(w_{0}^{*}-\tau\right) .
\end{aligned}
$$

Taking into account that the proportion of newly unemployed workers without informal income is $\delta_{0} /\left(\delta_{0}+\delta_{I}\right)$ and the proportion of those workers with informal income is $\delta_{I} /\left(\delta_{0}+\delta_{I}\right)$, the total value that the government must maximize is

$$
r W_{0}=\frac{r}{\delta_{0}+\delta_{I}}\left[\delta_{0} U_{0}+\delta_{I} U_{I}\right]=\frac{\delta_{0}}{\delta_{0}+\delta_{I}} u\left(w_{0}^{*}-\tau\right)+\frac{\delta_{I}}{\delta_{0}+\delta_{I}} u\left(w_{I}^{*}-\tau\right) .
$$

Notice that for our derivation in Section 2, it is equivalent to assume that $\delta_{0}=0$ and $\gamma_{0}=0$, so that all workers are displaced to informal jobs and do not lose this income. Alternatively, when $\delta_{I}=0$, such that workers do not have informal income after layoffs, the only relevant reservation wage is $w_{0}^{*}$. In both of these cases, the government must maximize the net reservation wage of displaced workers at the beginning of the unemployment spell. When both $\delta_{0}>0$ and $\delta_{I}>0$, the welfare of the unemployed is a monotone function of both reservation wages, properly weighted.

We now analyze the case of CARA preferences. Let $\omega \equiv u^{-1}\left(r W_{0}\right)$ be the monetary flow 
value that represents the welfare of the unemployed. Then, it can be shown that

$$
\frac{d \omega}{d b}=\hat{\alpha} \frac{d\left[w_{0}^{*}-\tau\right]}{d b}+(1-\hat{\alpha}) \frac{d\left[w_{I}^{*}-\tau\right]}{d b},
$$

where $\hat{\alpha} \equiv \delta_{0} u\left(w_{0}^{*}-\tau\right) /\left[\delta_{0} u\left(w_{0}^{*}-\tau\right)+\delta_{I} u\left(w_{I}^{*}-\tau\right)\right]$ is the relative weight in the formula of unemployed and informal workers in the newly unemployed. Thus, the changes in after-tax reservation wages, properly weighted, measure the change in the welfare of workers covered by UI.

It would be interesting to compute reactions from both $w_{0}^{*}$ and $w_{I}^{*}$ to UI changes. However, we do not observe the type of worker in our data and thus we estimate the change in average net reservation wage weighted by the proportion of each type of worker. We do not think that this is a major drawback, however. Given the high transition rates between unemployment and informality (shown in Section 3) and the relatively low informal wage, the difference between $U_{0}$ and $U_{I}$ should be low, meaning that the difference between $w_{0}^{*}$ and $w_{I}^{*}$ would be small.

In any case, changes in the welfare of the unemployed are measured through changes in net reservation wages. For example, if the importance of informal income increased because of UI reforms, this increased importance will be reflected in the reservation wages of equation (A.13). This is also true if workers change their search efforts in informal jobs, as Shimer and Werning (2007) show while discussing the effects of heterogeneity in their formulas.

It is important to consider the effect of this setup on the government's budget. Under this setup, the separation rate in equation (A.10) would be $\delta=\delta_{0}+\delta_{I}$ and the finding rate, $\phi_{u}$, would be a weighted average of the two finding rates determined by $\lambda_{0}\left[1-F\left(w_{0}^{*}\right)\right]$ and $\lambda_{I}\left[1-F\left(w_{I}^{*}\right)\right]$. In our data, we measure the total effect of $\phi_{u}$ without the possibility of measuring each of the two groups separately. However, this is not a drawback because what matters to the government's budget is the elasticity of this finding rate with respect to changes in UI. Whether the finding rate changes within each group or because of a composite effect is immaterial.

\section{B A brief description of databases}

SIPA A main source for our work was the administrative databases from the Social Security ("Sistema Integrado Previsional Argentino", SIPA). These are social security records of all firmsworker links at monthly basis. We used a particular version of SIPA database, which follows the jobs (worker in a firm) providing the level of wages for that job at monthly level. From this source we were able to construct a full working history of the workers, month by month, from January 1995 to December 2009. This allowed us to generate variables related to the jobs previous to UI, and to identify declared re-employment jobs.

Self employed The Self employed database has only an identification variable by month (from 1995 to 2009) which is 1 if the worker has declared himself as self-employed in that month and paid the contributions. This source is important for analyzing re-employment: if worker is observed as self-employed in any period after the beginning of UI, he is considered reemployed. 
UI beneficiaries The UI Beneficiaries database (UBd) is used for administrative purposes. It has information of all the monthly UI transfers for each worker. It also records additional variables, such as pre-unemployment wages, age of the worker, gender, UI eligibility duration and others.

\section{B.1 The Unemployment Duration database}

Combining SIPA, self-employed database and UBd we construct our database. It consists of all the UI covered spells that began after layoffs between 2005 and 2007. We collected all the information of these workers in SIPA and Self-employed databases. We finally summarized the information including the relevant variables from previous jobs (pre-unemployment contributions, last job tenure, last job wages, industry and location) and from the re-employment job (wage, duration, industry and location). We also identified whether the worker reemploys as a self-employed. In that case, we only observe employment status and we do not use these observations for wage analysis.

In this way, we constructed the Administrative Unemployment Duration database (AUD) that was used for duration analysis and impact evaluation of policies. Particular variables are described below.

spell Number of UI spell

ntransfer Number of UI transfer of each spell (months in UI)

period Year and month of the UI transfer

age Age of the worker at the moment of the beginning of UI

gender Gender of the worker

type Whether the worker is a permanent worker or a construction worker

spouse Whether the worker has a spouse

children Number of children of the worker

totaltransfers Entitlement of UI duration (number of transfers that the worker is entitled to receive)

maxWage Wage used to compute the UI transfer (best wage of the last 6 months previous to UI)

basictransfer Amount of basic UI transfer

family Amount of family allowances

totaltransfer Amount of total UI transfer

contributions Number of contributions in the three years previous to layoff

tenure Tenure in the last job 
tenure_cens Whether tenure is censored

meanWage Mean of wages in the last six months previous to layoff (from SIPA)

maxWage Max of wages in the last six months previous to layoff (from SIPA)

lastWage Wage at the moment of layoff

begining_lastjob Period of the beginning of the last job

end lastjob Last period in which the worker is with a job before the unemployment spell

location Location of the last job

industry Industry of the firm of the last job

layoff Layoff period

beg_self Period of the first declaration as self-employed after UI

contr_self Number of contributions in the first year of re-employment job as wage earner

beg_wage Period of the first declaration as wage earner after UI

firstWage First wage of re-employment job as wage earner

mean1yearWage Mean of wage in the first year of re-employment job as wage earner

location reeployment Location of re-employment job

industry_reeployment Industry of the firm of re-employment job

imputedSP Imputation of severance pay

FirstReemployment Period of the first re-employment job (both as wage earner or self-employed)

\section{Parameters for calibration}

In this section we will describe how we compute the parameters of Table 13.

Finding rate, $\phi$ Computed through survival analysis applied to the unemployment durations in AUD.

Separation rate, $\delta$ Computed through separation rates from the "Encuesta de Indicadores Laborales", a survey to firms hirings and separations.

Unemployment rate, $u$ Computed through finding and separation rates, as the steady state unemployment rate, $u=\delta /(\delta+\phi)$. 
Benefit level, $b$ Maximum level of benefit at 2006.

Benefit level at UI extension, $b_{B}$ Level of benefit after $B$ periods. It changes according to the exercise.

Unemployment benefits exhaustion probability, $\gamma$ Computed as $\gamma=1 / B$, where $B$ is UI eligibility.

Level of severance pay, $S$ Severance pay is computed using SP rules over average worker (tenure, pre-unemployment wage).

Wage inequality, $w^{*} / \widehat{w}$ We approximate $w^{*}$ as the unemployment income $(b+y)$.

Duration of UI benefits, $B$ Mean duration of UI benefits.

Expected duration of UI benefits, $D_{B}$ We approximate this as $D_{B}=1 /(\phi+\gamma)$, where we compute $\phi$ as the mean finding rate in $B$ periods.

Duration of UI benefits extension, $E$ Number of months of UI extension, weighted by the proportion of workers considered in each exercise.

Expected duration of UI extension, $D_{E}$ We approximate it as a weighted average of $1 /\left(\phi_{E}+\right.$ $1 / E)$, where $\phi_{E}$ is the mean finding rate for the periods considered in $E$.

Survival up to B, $p_{0, B}$ Proportion of workers that exhaust UI at its ordinary duration.

Unemployment duration, $D$ Computed as $1 / \phi$.

\section{C.1 Estimation of the variance of wage offers}

The computation of $\Lambda$ depends on the variance of wage offers and of re-employment wages. We use the Heckman selection model to compute these estimates. We first estimate the variance of the residuals of a regression of the log of wages on observables. Second, we compute a Heckman selection model that gives an estimate of $\sigma$ once controlling for the same covariates. Finally, we compute $\Lambda$ using these estimates. 


\section{Alternative elasticities}

Table D.1: Elasticities from alternative estimation techniques

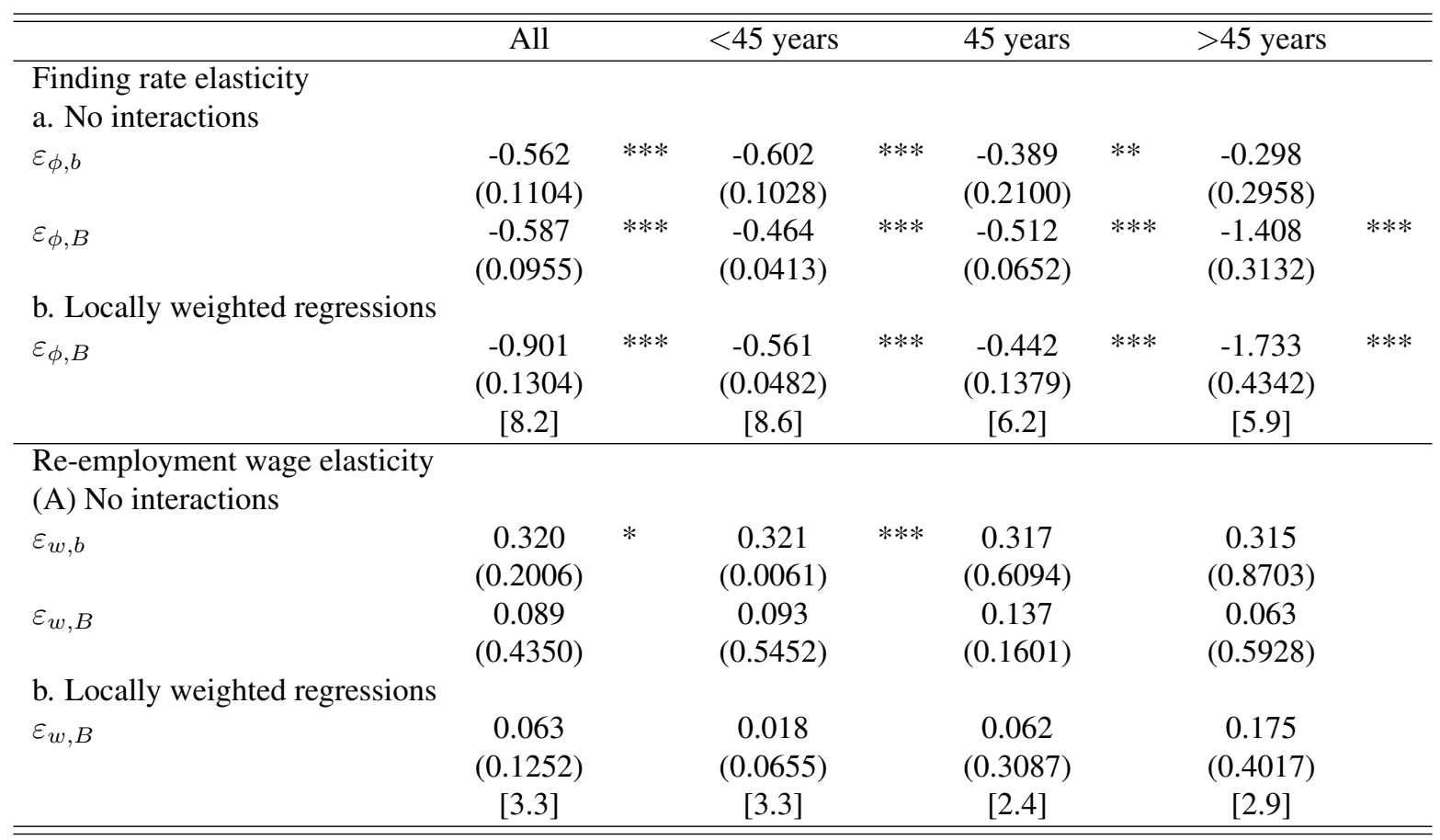

Notes: Each cell of the table represent an elasticity by computing the weighted average of different estimates. These elasticities differ from those in table 12 in that we used alternative techniques, as described in Section 6.3. Panels (A) reproduce elasticities from models in which we eliminate the interaction between the polynomial of the running variable and the treatment variable and panels (B) reproduce elasticities from regression discontinuity models with local triangular weights within a bandwidth. Bandwidths reported in square brackets are in units of the running variable and are the weighted average of bandwidths used in the regressions implied in the computation of each elasticity. Numbers in parentheses are standard deviations. Statistical significance: * significant at the $10 \%$ level; ** significant at the $5 \%$ level; *** significant at the $1 \%$. level. 
Table D.2: Welfare analysis using alternative estimates

\begin{tabular}{lcccc}
\hline \hline & All & $<45$ years & 45 years & $>45$ years \\
\hline (A) No interactions & & & & \\
(1) UI level, search effort & 0.055 & 0.024 & 0.021 & 0.171 \\
(2) UI level, reservation wage & 1.241 & 1.008 & 1.216 & 1.258 \\
(3) UI duration, search effort & 0.053 & 0.301 & 0.007 & -0.030 \\
(4) UI duration, reservation wage & 0.986 & 0.985 & 0.521 & 1.084 \\
& & & & \\
(B) Locally weighted regressions & & & & \\
(3) UI duration, search effort & 0.023 & 0.111 & 0.031 & -0.044 \\
(4) UI duration, reservation wage & 1.234 & 0.980 & 1.647 & 0.516 \\
\hline \hline
\end{tabular}

Note: Each cell in the table represent an indicator of the welfare gain of modifying the UI system as in table 14 in the main text, but calibrating the formulas using the elasticities from table D.1. 


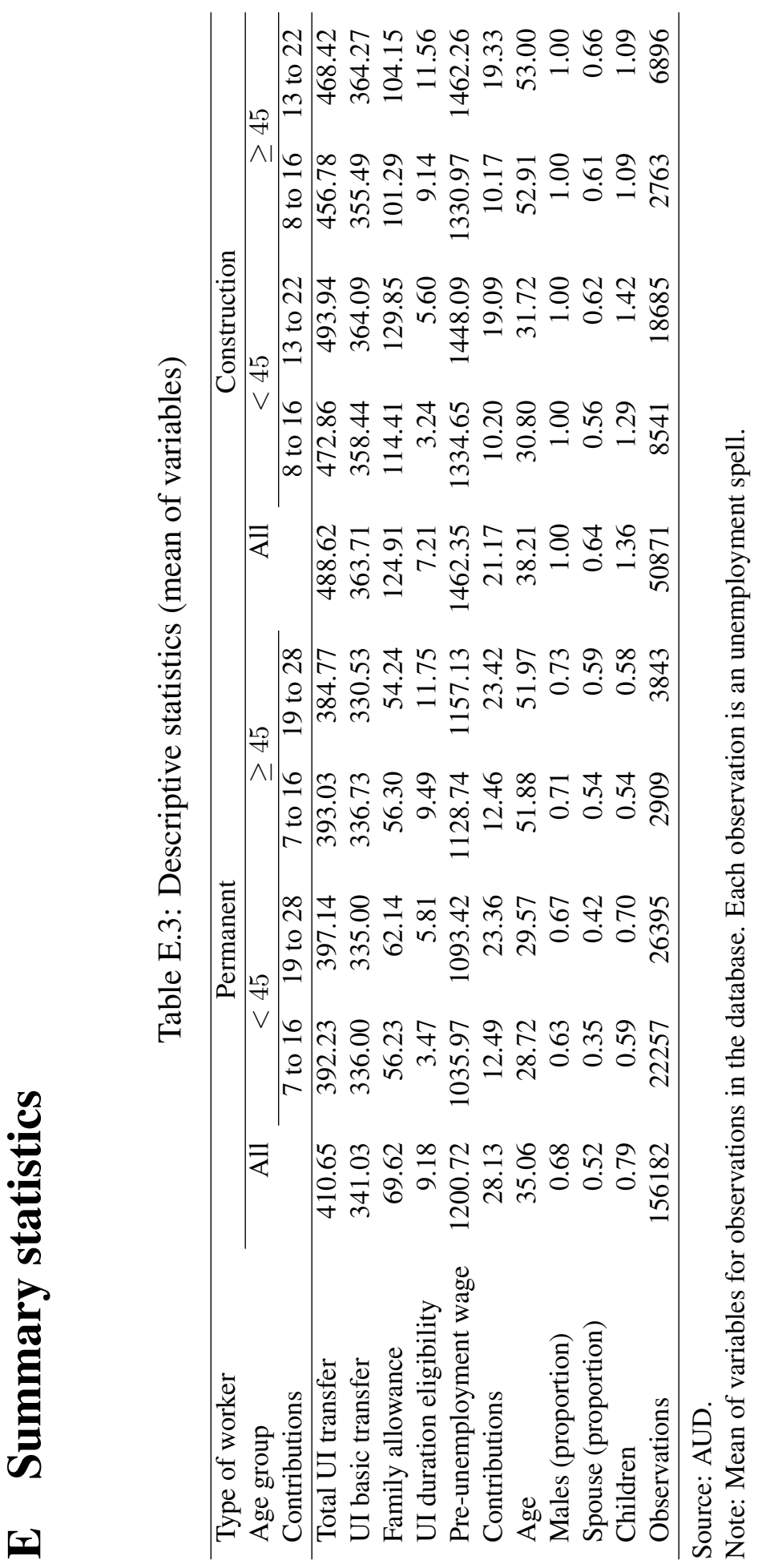

